\title{
Critical review of design principles for rock support in burst-prone ground - time to rethink!
}

\author{
P.K. Kaiser Bharti School of Engineering, Laurentian University, Canada \\ M. Cai Bharti School of Engineering, Laurentian University, Canada
}

\begin{abstract}
In the 1980s, severe rockbursting in underground mines, in Canada, Chile, South Africa, and other countries, caused many fatalities and was recognised as an unacceptable work place hazard. Since then huge advances have been made in seismic monitoring, energy release control by improved mining methods, ground control with innovative and effective rock support systems, and advanced risk hazard management procedures. As a result, many burst-prone mines have achieved outstanding safety records and the industry has benefited by developing means of accessing highly stressed orebodies at depth. In 1995, the Canadian Rockburst Research Program was completed and guidelines for rock support selection were published. Since then many researchers around the world have further advanced the state-of-the-art of support selection and many entrepreneurs have provided industry with a sophisticated tool box full of effective rock retention and support components and systems.
\end{abstract}

Most of these advances and the design of these tools, however, are based on some fundamental assumptions, i.e. that seismic events create ground motions that damage excavations, and thus load and potentially damage the ground support. It is therefore often implied that the source of energy which causes damage stems from mining-induced seismic events. In this paper, we critically assess the support design guiding principle, which leads to the identification of three facts with serious practical implications: (1) standard, assumed ground motion patterns are unacceptably flawed; (2) ground motion-related energy transfer mechanisms rarely constitute the main source of support loading; and (3) dynamically stressed rock fails by brittle, extensional failure causing disproportional excavation convergences and support damaging deformations.

The keynote papers presented at this symposium in Australia and at the Eighth International Symposium on Rockbursts and Seismicity in Mines in Russia describe these flaws and recent advances to overcome related deficiencies. It is concluded that the primary damage mechanism often is a seismically triggered strainburst or a dynamically loaded strainburst, and damage is rarely dominated by momentum transfer or dynamic shaking. Consequently, rockburst damage is primarily related to the state of stress and the local mine stiffness at the potential damage location and not or only indirectly related to the seismic ground motion. Field evidence is used to illustrate and support this interpretation.

\section{$1 \quad$ Preamble}

Due to the complexity of the topic of rock support in burst-prone ground and the critical nature of the underlying concept, I have asked the symposium committee to accept complementary, in parts overlapping, written versions (Kaiser and Cai, 2013a, 2013b) of two keynote addresses to be held within a five month window in Australia and in Russia. Each paper stands alone but different emphasis is placed on strongly interlinked topics of brittle rock failure and dynamic failure modes, support design principles and methods, and flaws in current approaches that need to be overcome to further improve safety in burstprone mines.

These papers present in large parts personal perspectives on a most challenging engineering design issue, support in burst-prone ground, perspectives that have not yet found wide acceptance and thus may be controversial to some extent. Potential misconceptions and misinterpretations are addressed and naturally 
will put some published results, opinions, and conclusions in question. As the title indicates, in the authors' opinion, it is 'time to rethink' before moving forward. All critiques, explicit or implied, whether scientifically supported or only based on a qualitative assessment of the state-of-the-art, are intended to serve as a foundation for future discovery and, as an incentive for the next step, change in ground control for burstprone mines.

\section{Introduction}

The Canadian Rockburst Program was completed in 1995 and the Canadian Rockburst Support Handbook (CRBSHB), which presents an engineering approach to selecting rock support for burst-prone mines by systematically assessing both support demands and support capacities, was published in 1996 (Kaiser et al., 1996). In recent years, many new rock support components have been developed to enhance the ground control toolbox and new test data are available to better assess the dynamic performance of rock support. Data processing tools were developed to better assess the risk of bursting and burst damage. Furthermore, it was learned that one of the most important rockburst damage processes, called seismically triggered strainbursts, often dominates the failure process when the rocks are statically highly stressed and, in some cases, dynamically loaded by a remote seismic event. This is a process that was not fully recognised and reflected in the engineering approach presented in the 1996 handbook.

After more than a decade, this handbook is now being updated in the form of a 'Rockburst Support Selection Guide' by Cai and Kaiser (2013) to assist practicing engineers in following systematic design procedures. Even though it is realised that further research and verification studies will be required to arrive at proven design procedures to deal with seismically triggered and dynamically loaded strainbursts, this important aspect will be included in a qualitative manner and is addressed in the keynote lectures.

Realising that the interaction of geology, variability in material properties, stress and dynamic factors leads to a highly complex process of rockburst damage and damage mitigation with ground support, Centre for Excellence in Mining Innovation (CEMI) has, in collaboration with MIRARCO at Laurentian University, developed a 3D support demand assessment and support selection tool called BurstSupport (Cai and Kaiser, 2011; Cai et al., 2012). The underlying design principles rely on a scaling law to anticipate design ground motions (peak particle velocity $\left(p p v_{D}\right)$ or peak particle acceleration $\left(p p a_{D}\right)$ ) from seismic sources. Today, as then, this design assumption is an acceptable approximation for engineering purposes. This statement is often questioned and the use of scaling laws for design will be addressed in this paper. When designing support, it is necessary to arrive at meaningful design inputs, i.e. ground motion thresholds that are justified but not excessively conservative. The scaling law approach aims at providing such meaningful design inputs.

However, when assessing rockburst damage during forensic analyses or case studies, it is necessary to obtain actual ground motions (ppv or ppa) that reflect the true radiation patterns and wave reflections, ground motions that differ significantly from those determined by scaling laws. In collaboration with the Institute for Mine Seismicity (IMS), CEMI has developed a synthetic ground motion assessment tool, called S-GMAT. This tool provides analytical and numerical solutions for 3D radiation patterns generated by point sources with assumed or measured source parameters (source size, stress drop, magnitude or moment, and slip direction).

From reading the relevant literature and involvements with deep civil tunnels and mines managing burstprone ground, it is quite evident that there are many misconceptions and deficiencies in the manner by which burst-resistant support is designed or selected. In this paper, elements of the current understanding of dynamic, brittle rock failure and the role of support are reviewed, and deficiencies and possible solutions are discussed to guide future research and engineering works. The key elements for understanding rock failure and for designing support in burst-prone ground are illustrated by Figure 1 and these elements are covered to different extents in this written version of the keynote addresses. 


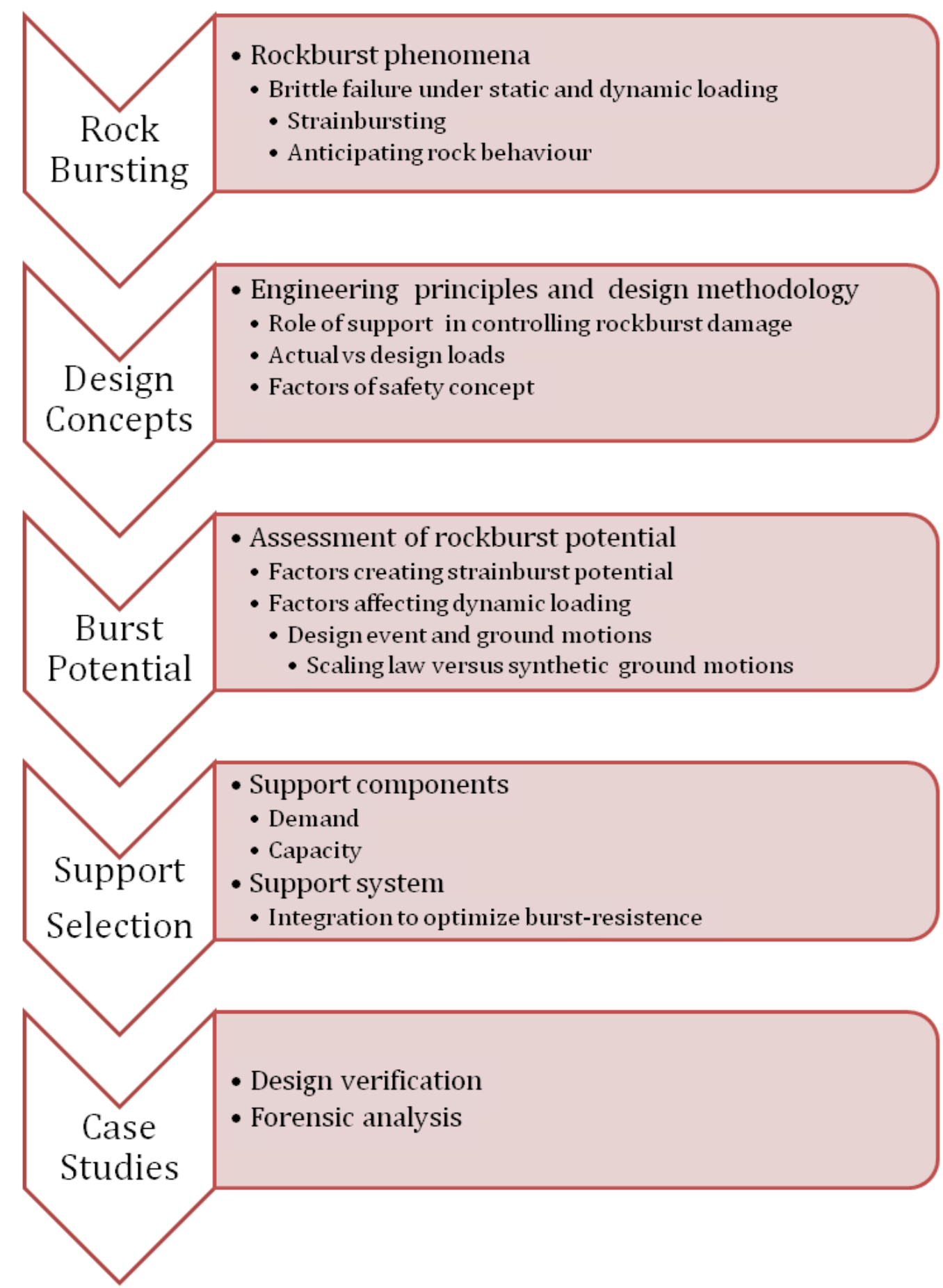

Figure 1 Five key elements for understanding dynamic rock failure and guiding rockburst support design

This chain of comprehension and design steps is covered in detail in the 1996 CRBSHB. This paper focuses only on those concepts that are either misunderstood or have been discovered since the handbook was written. The reader is still referred to the CRBSHB for specific aspect of support selection. 


\section{$3 \quad$ Rockburst phenomena}

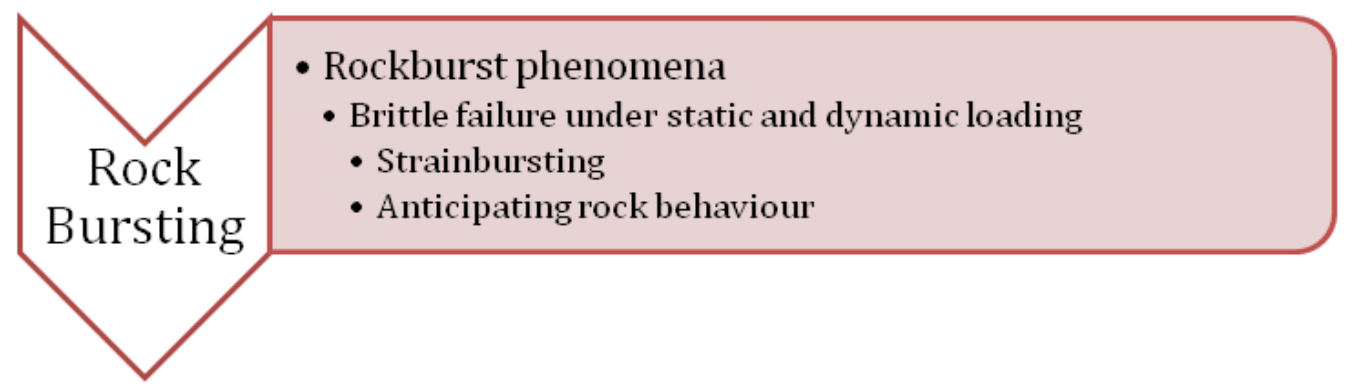

A rockburst is defined as damage to an excavation that occurs in a sudden and violent manner and is associated with a mining-induced seismic event. This general term 'rockburst' is independent of the cause of damage and thus is used for strain, pillar and fault slip bursts (see Section 3.3). Depending on the burst type, a partial cause for damage may be one of the three: a stress wave may magnify near an excavation, adding a temporary additional stress to the mining-induced stress field; the stress wave may accelerate rock, adding to the gravitational forces; or the wave may cause ground motions (particle velocities) at the excavation boundary, adding energy to blocks of rock. In all three cases, though, the damage process is a sudden rock failure due to both static and dynamic loading of the rock beyond its capacity and is associated with sudden rock mass bulking (see Section 3.2 ) and potentially rock ejection.

\subsection{Brittle rock failure under static and dynamic loading}

Before assessing rockburst damage and rock damage under dynamic loading conditions, it is necessary to understand brittle failure processes near excavation under pseudo-static conditions. When dealing with burst-prone ground, the rock mass typically is hard and brittle ${ }^{[1]}$ such that it fails by extension fracturing or tensile stress-induced spalling (e.g. Kaiser et al., 2000; Martin, 1997; Diederichs, 2003; and many others). By implication, this paper relates to conditions encountered at elevated high stress levels, in massive to moderately jointed ground, e.g. ground with GSI > 65 (Kaiser, 2006). Understanding brittle rock failure is extremely important for the interpretation of rockburst damage. When a brittle rock mass is loaded, inherent heterogeneities in the rock mass, in the intact blocks or the jointed block assembly, lead to differential and extensional straining (as in a trellis; Trollope (1968)) or slip along cracks, fractures of joints. This in turn causes internal tensile stresses which then lead to Griffith-crack-like propagation of tensile fractures. These fractures disrupt the rock mass, by breaking rock bridges or intact rock blocks or by shearing and opening critically oriented discontinuities (Figure 2).

In other words, stress-driven failure leads to rock 'fragmentation', particularly in the low confinement zones near excavation boundaries, that creates broken rock of varying fragment sizes and shapes. Most importantly, a continuum or tight discontinuum, often with non-persistent joints, is transformed into a 'loose', cohesionless discontinuum with mostly continuous and open fractures. This broken rock mass is then prone to ravelling if not well supported with a deformation compatible retention system. Brittle failure by tensile spalling occurs if the calculated elastic stress path moves above a damage threshold and to the left of the spalling limit (Kaiser and Kim, 2008). Hence, for underground excavations, stability and failure processes are controlled by processes that occur in the low confinement range. 


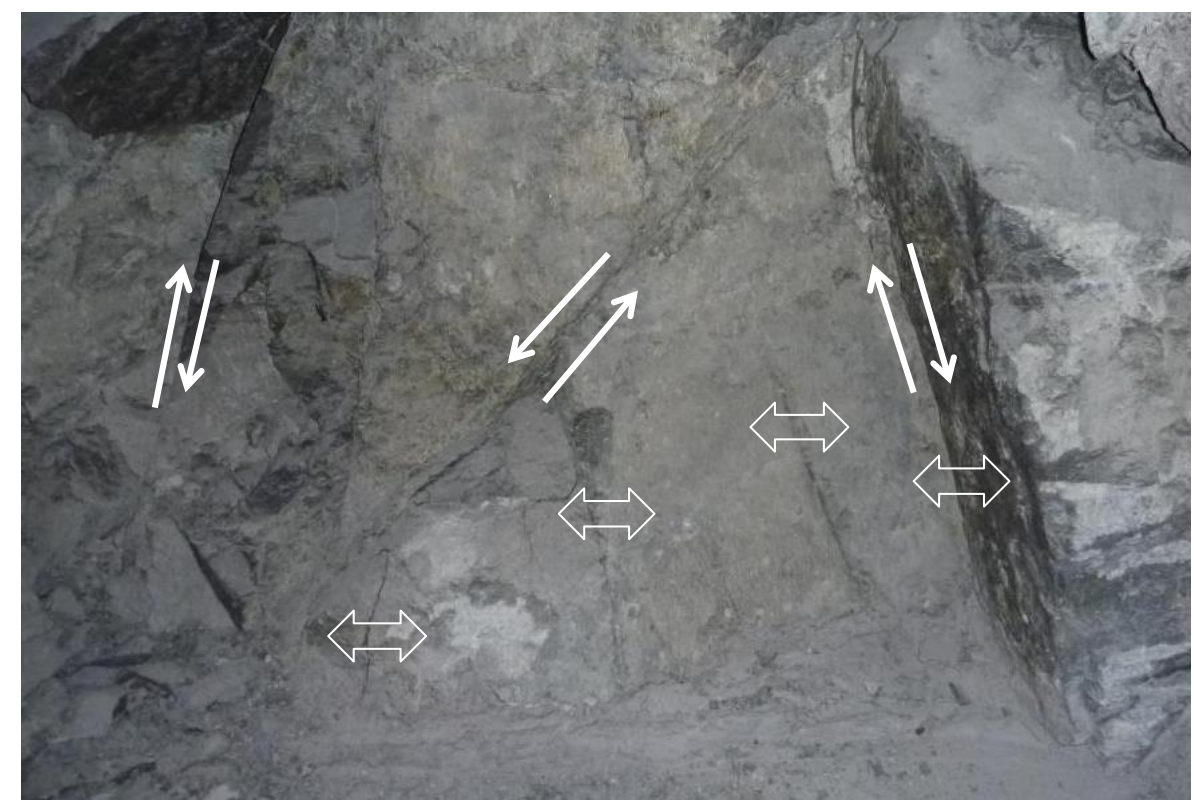

\section{Figure 2 Stress-fractured ground near an excavation showing both shear (reverse arrows) and extensional movements (open arrows)}

If stressed beyond the initiation threshold and to the left of the spalling limit, the volumetric deformation characteristic of brittle failing rock changes drastically as geometric incompatibilities between fractured rock fragments lead to high, uni-directional volume increases, called bulking. This volume increase is highly dependent on the confinement; for typical support pressures of less than $1 \mathrm{MPa}$, the anticipated bulking may reach or exceed 7 to $10 \%$ at $\sigma_{3}<0.1 \mathrm{MPa}$ (Kaiser et al., 1996).

In brittle failing rock where stress-driven failure leads to a zone of fractured rock near an excavation, engineering for constructability basically involves three aspects:

- Retention of broken rock near an excavation.

- Control of deformations due to bulking of the fractured rock.

- Dissipation of energy by the supported, fractured rock mass if failure occurs in a violent manner.

These three aspects of broken rock management are reviewed here and the reader is referred to Kaiser et al. $(1996,2000,2005)$ and Kaiser (2005) for constructability issues and related matters.

\subsection{Anticipating rock mass behaviour under static loading}

Rock mass behaviour and failure modes near underground excavations can be grouped according to stress level (SL) and degree of natural jointing (Hoek et al., 1995). By relating the SL to $\sigma_{\max }=3 \sigma_{1}-\sigma_{3}$, normalised to the uniaxial compressive strength (UCS), rather than to the major principal stress $\left(\sigma_{1}\right)$ alone, two important aspects were integrated in the tunnel behaviour matrix (Kaiser et al., 2000): (1) stress-driven failure near excavations is sensitive to the stress ratio $\sigma_{1} / \sigma_{3}$, and (2) this stress ratio and thus the SL may change with mining, implying that the failure mode may also change during mining.

At intermediate stress, typically starting at $\sigma_{\max }>\sim 0.4$ UCS ${ }^{[2]}$ or $S L>0.4$, intact rock fracturing starts to overlap with structurally-controlled failure processes. While stress-driven fracturing may not yet add much load to the support system, overbreak increases and 'loose ground' starts to form. Popping ground and minor strain-bursting, in massive to moderately jointed ground, has to be anticipated. 
At high stress, typically at SL greater than 0.65 , in strong hard rock, deep-seated stress-driven failure dominates. The rock mass surrounding the tunnel is heavily fractured and early installed, effective support to retain broken rock is needed. Furthermore, due to geometric incompatibility between strong, broken blocks of rock, heavily fractured ground tends to rapidly increase in volume when strained. This process is called geometric bulking and is schematically illustrated by Figure 3 on a Voronoi analogue. When loaded parallel to the excavation boundary (axially in the element illustrated in the figure), the lateral deformation is first proportional to the axial strain (defined by the Poisson's ratio and the Young's modulus), but then deviates from linearity as soon as the peak strength is reached.

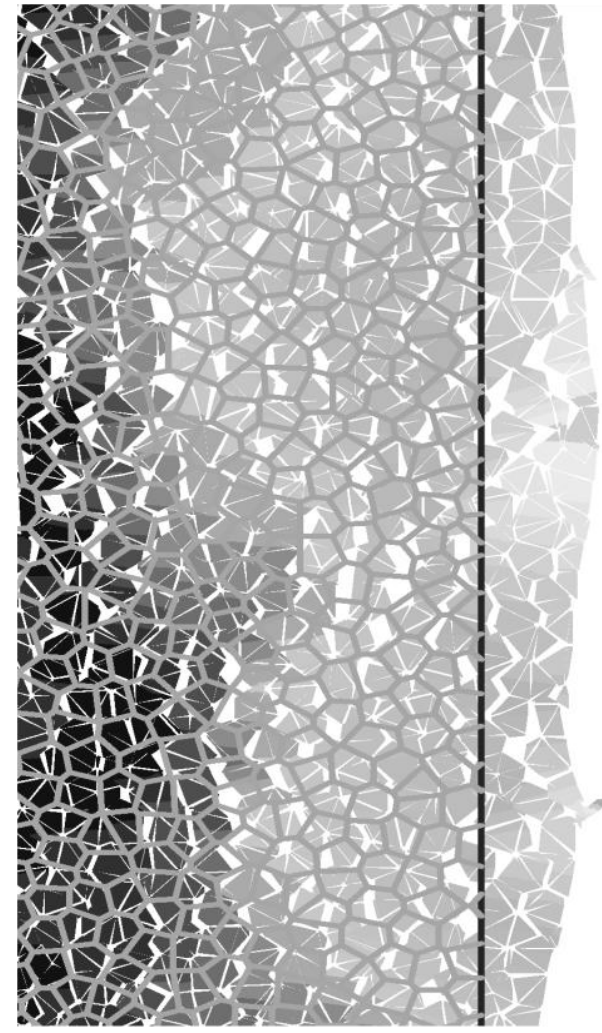

(a)

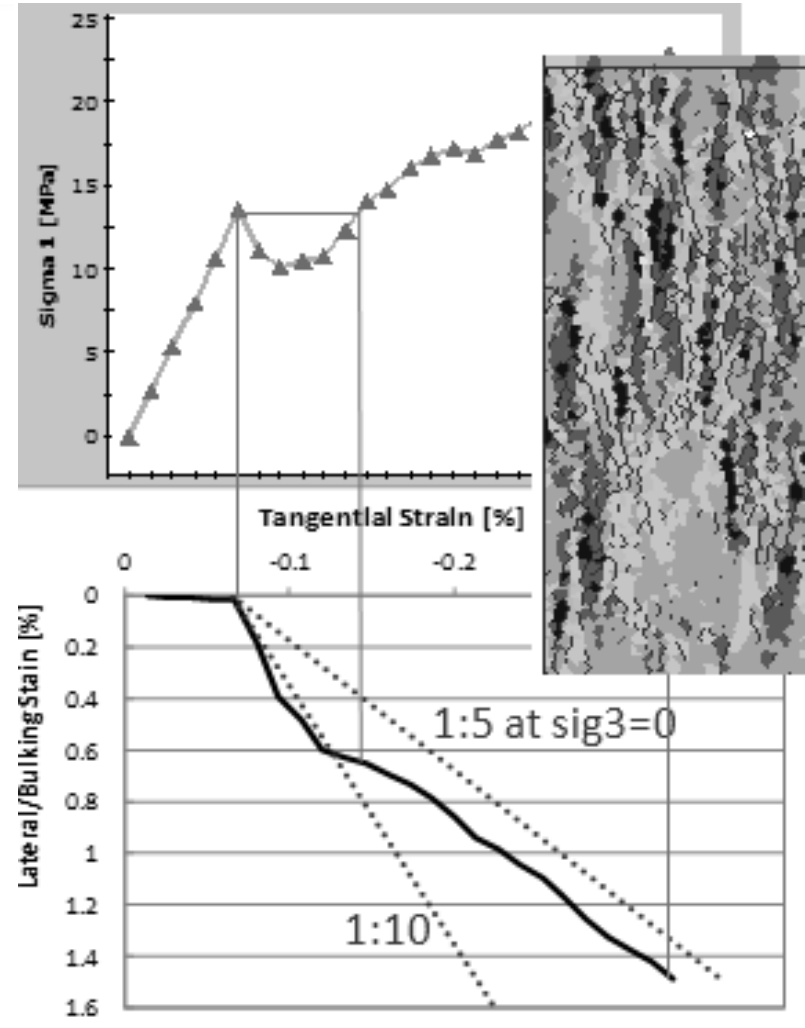

(b)

Figure 3 (a) Voronoi analogue of a rock mass consisting of high strength blocks (deformation is dominated by geometric non-fit of block geometries); (b) axial (tangential) and lateral (bulking) strain as model is loaded; insert shows block boundary separation (grey lines) and stress flow (light to dark shades)

In this schematic model, the axial to lateral strain, which corresponds to the tangential to radial strain for a volume element of rock near the excavation, increases disproportionately as the peak strength is reached. For this analogue in unconfined state, the ratio of tangential to radial strain in the post-peak range is 1:10, meaning that for every $1 \mathrm{~mm}$ of tangential deformation there will be $10 \mathrm{~mm}$ of radial convergence. Interestingly, after some strain, the Voronoi analogue can carry increasing stress (as a result of noncritically oriented block boundaries) and the rate of bulking reduces gradually to about 1:5 as vertical columns of stable blocks carry load.

Because broken rocks can only move toward the excavation, this bulking causes large, non-elastic wall deformations, i.e. the direction is controlled by the excavation geometry and thus is not a constitutive material parameter.

As a consequence of the spalling and bulking processes, serious deficiencies in predicting rock mass behaviour and resulting support designs must be expected when constitutive models, developed to simulate soil behaviour in a continuum framework, are applied to predict deformations of brittle failing rock. While the volume of rock involved in the observed transition from continuum to discontinuum 
behaviour can be anticipated by use of conventional modelling tools, e.g. by the approach presented by Diederichs et al. (2007), the related bulking must be considered separately when selecting ground control methods under both static and dynamic failure conditions.

\subsubsection{Depth of failure}

For support design purposes, the depth of failure $d_{f}$ is defined as the depth measured from a circle or circular arch circumscribing the excavation to unstable or potentially unstable rock ${ }^{[3]}$. The normalised depth of failure $d_{f} / a$, depth of failure $d_{f}$ normalised to the tunnel radius $a$, can be obtained from the wellestablished semi-empirical relationship between the depth of failure of stress fractured ground and the stress level SL (Kaiser, 2006, based on Kaiser et al., 1996; Martin et al., 1999):

$$
\frac{d_{f}}{a}=C_{1} \frac{\sigma_{\max }}{\sigma_{c}}-C_{2}=C_{1} S L-C_{2}
$$

For static conditions, the constants are on average $C_{1}=1.37$ and $C_{2}=0.57$ (Kaiser, 2006). This relationship is not applicable for falls of ground where the depth of failure is controlled by stress relaxation and gravity rather than by mining-induced stress increases.

\subsubsection{Rock mass bulking factor}

Rock mass bulking refers to a volumetric or uni-directional length change as the rock mass is strained during the stress-driven failure process (Figure 3). It is highly dependent on confinement and is much larger near an excavation than when confined. Bulking includes geometric volume increases resulting from a geometric non-fit of hard, strong rock blocks (or fragments). Because broken rock can only move into an excavation in the radial direction, the bulking factor (BF) is defined as the ratio of change in length $d_{l}$ perpendicular to the excavation boundary over an original length (I):

$$
\mathrm{BF}=d l / l ; \text { if } I=d_{f} \text {, then } \mathrm{BF}_{d f}=d l / d_{f}
$$

Based on the available field evidence and numerical modelling (CRBSHB; Cai et al., 2010; Cai and Kaiser, 2007), this geometric, radial bulking factors varies from as little as 1 to $50 \%$ depending on the severity of damage, the shape of the rock fragments and the effectiveness ${ }^{[4]}$ of the support system. Table 1 provides approximate rock mass bulking factors for estimating the uni-directional strain in the failure zone.

\begin{tabular}{|c|c|c|c|}
\hline Location and Support Condition & $\begin{array}{l}\text { Average Support } \\
\text { Load Capacity } \\
\left(\mathrm{kN} / \mathrm{m}^{2}\right)\end{array}$ & $\begin{array}{c}\text { Recommended } \\
\text { Bulking Factor } \\
\text { (BF) }\end{array}$ & $\begin{array}{l}\text { Severity of } \\
\text { Anticipated } \\
\text { Damage }\end{array}$ \\
\hline \multirow[t]{2}{*}{ Floor heave } & 0 & $30 \pm 5 \%$ & Minor to moderate \\
\hline & & $>50 \%$ & Major \\
\hline Walls and backs & $<50$ & $10 \pm 3 \%$ & Minor to moderate \\
\hline \multicolumn{4}{|l|}{ Light standard bolting and loose, light mesh } \\
\hline Yielding support & $<200$ & $5 \pm 1 \%$ & Minor to major \\
\hline
\end{tabular}

Table 1 Rock mass bulking factors (BF) (Kaiser et al., 1996)

[3] If the depth of failure is determined by field observations on supported ground, it is necessary to differentiate between continuously broken ground and stress-damaged ground; $d_{f}$ is not the distance to the last observable fracture in a borehole.

[4] Effectiveness of a support system with respect to bulking control is not synonymous to confining pressure. Even light reinforcement can prevent extension fractures from opening and thus reduce bulking. 


\begin{tabular}{l}
$\begin{array}{l}\text { Strong support with rock mass } \\
\text { reinforcement }\end{array}$ \\
\hline
\end{tabular}

The wall displacement component due to bulking $u_{w}$ can be estimated by multiplying the thickness of failed rock (baggage plus depth of failure $d_{f}$ ) by the average bulking factor BF. Assuming that the maximum baggage (defined in the 1996 CRBSHB) is $21 \%$ of the drift height (typical for square or rectangular drifts), an estimate of the maximum wall displacement can be obtained from:

$$
\frac{u_{\text {wall }}}{a}=B F(1.34 S L-0.57( \pm 0.05))
$$

Where $u_{w}$ is the maximum displacement and $a$ the radius of a circle circumscribed around the opening.

As will be discussed in Section 4.3 on the role of support, three types of deformation control measures are required to manage such broken ground: (1) reduce bulking by reinforcement of the fractured rock mass; (2) retain broken rock with a deformable retaining system; and (3) hold package of reinforced rock back to stable ground.

\subsection{Anticipating rock mass behaviour under dynamic loading - rockbursting}

If the previously described failure process involving stress fracturing and rock mass bulking occurs in a sudden and violent manner, it is called a rockburst. Accordingly, the damage process is a sudden, violent fracturing of rock near an excavation. While one typically differentiates between three rockburst types (pillar bursts, fault-slip bursts, and strainbursts), from a support design perspective, they all cause damage to the excavation wall, roof or back and floor. The cause may differ but the effect is the same: in a fault-slip burst, a seismic wave may radiate from the source and cause damage; in a pillar burst, stress may be redistributed and cause damage; and in a strainburst, the stress near the excavation wall may exceed the rock mass strength and cause damage. The resulting damage, reflected in a fragmented rock mass, causes a sudden increase in volume, produces sudden convergence or floor heave, and, if not properly supported, may unravel and fall under gravitational and dynamic shaking forces, or may be ejected by wave reflection or energy transfer processes from incoming waves or by momentum transfer from larger to smaller rock blocks.

There are three sources of energy that can cause damage and must be contained by support:

1. In strainbursts, energy is stored in rock surrounding the excavation. It is a function of the strength of the rock mass near the excavation, the post peak stress-strain slope of the failing rock mass, and the local stiffness of the loading system, called mine stiffness.

2. During pillar bursts, the strain energy stored in a pillar and the surrounding rock is released. It is a function of the pillar strength, its post peak load-displacement slope, and again the local mine stiffness. Note: if only the skin of a pillar fails, it should be classified as a mining-induced strainburst or face burst.

3. When a fault slips, i.e. during a fault-slip event, energy radiated from the seismic source results in a dynamic stress wave. This energy and the related stress change is a function of the event intensity (magnitude, seismic moment, etc.) and distance from the source. However, there is also strain energy stored in the rock near the location where damage is triggered or caused by the stress wave. This frequently ignored stored strain energy, as for strainbursts, depends on the strength and the post peak stress-strain slope of rock mass and the local mine stiffness.

In other words, for all three rockburst types, the energy stored in the rock before a rockburst and the local mine stiffness must play a role in the damage process and affect the severity of damage, and needs to be considered in support design. This very important point is often ignored, e.g. when damage is directly linked to ground motion intensity. By analogue, the amount of water spilled from a glass of water during dynamic shaking largely depends on the water level in the glass. If the glass is full, any dynamic shaking will 
trigger spillage and the amount of spill will be directly related to the dynamic intensity but, if half full, no spillage will occur until a critical dynamic threshold is reached. It is therefore often not meaningful, or even acceptable, to relate damage to the intensity of a seismic event alone. Accordingly, support design approaches that relate damage to ground motion alone are flawed; the vulnerability of an excavation to damage must be taken into account.

\subsubsection{Excavation vulnerability}

From the above discussion, it follows that the vulnerability of an excavation depends on the stress level SL, relating near excavation stress to rock mass strength, the energy stored near the excavation considering the local mine stiffness, and the effectiveness of the rock support to control the consequences of damage (proximity to failure as defined by the safety margin with respect to load, deformation, and energy).

Heal et al. (2006) correctly identified this need and introduced an Excavation Vulnerability Potential (EVP) index, a concept that, based on the previous discussion, is highly relevant. The anticipated damage to an excavation clearly must be related to the vulnerability of an excavation, whether measured in terms of stress level, depth of failure potential, or safety margin of the supported ground. They suggested to rate the EVP by four (empirical) quantifying parameters: stress conditions (E1), ground support system capacity (E2), excavation span (E3), and influence of geological structure (E4). The resulting empirical EVP index has two components: a Damage Initiation Factor (E1 / E2) and a Depth of Failure Factor, (E3 / E4). The former accounts for local site parameters conducive to the generation of dynamic rock mass failure, and the later for the local site conditions that may increase the depth of dynamically induced rock mass failure. The EVP is the product of the two factors.

While the concept is a most valuable first attempt to take the excavation vulnerability into account and is conceptually correct, their approach mixes factors that affect different failure modes and thus requires refinement. The following current deficiencies will need to be overcome to improve the practical value of the concept. From the discussion presented previously as well as in the following sections on strainbursting and scaling law, the following opportunities for improvement exist:

- Stress conditions:

- because of the stress magnification effects, the stress level at the excavation wall, or the stress ratio of the maximum to the minimum local principal stresses $\left(\sigma_{1} / \sigma_{3}\right)$ need to be considered, e.g. to differentiate relaxation from stress-driven failure and to capture the magnifying effect of the stress ratio,

- the dynamic stress effect is likely overrated when compared with design ground motion $\left(p p v_{D}\right)$ obtained from a scaling law as radiation patterns, and near-field effects are ignored. Note: most cases in their database are strongly affected by this deficiency,

- the depth of failure factor is currently applied to falls of ground and stress-driven failures. This is likely flawed because the depth of failure concept was developed for assessing failed or fractured zones around an opening and thus is only applied to stress-driven failures and not to relaxation-related falls of ground.

- Ground support system capacity:

0 the capacity rating largely assesses retention and reinforcement components but not the holding/deformation capacity and the connection function. Furthermore, there is a need to separately rate load, displacement, and energy capacity, or to identify which of the three capacities determines the critical safety margin.

- Excavation span:

- this factor needs to be replaced or focused on falls of ground only. The span clearly affects the vulnerability for falls but not necessarily for stress-driven failures, unless the horizontal stress is high or the failure of the excavation walls leads to a subsequent ravelling of the back. 
- Influence of geological structure:

o this factor currently focuses on structural features that enhance the damage severity, particularly in seismically triggered falls of ground. Such structures, as discussed below, also influence the mine stiffness, and thus affect the strainburst potential and damage severity.

Detailed case studies, as described later, and in the section on forensic analysis are needed to arrive at a systematic rating system of the excavation vulnerability. This must include measures that differ for each failure mode, e.g. strainbursts versus falls of ground, that consider the effect of mine system stiffness, e.g. extraction ratio, and the support effectiveness in terms of the four support roles described below.

\subsubsection{Strainbursts}

A strainburst is a sudden and violent failure of rocks near an excavation boundary, with seismic source and damage being co-located. A strainburst may or may not be associated with ejection of rock fragments. Most, if not all, strainbursts are mining-induced, i.e. the burst is caused by a change in local stress and/or mine system stiffness due to tunnel advance or stope excavation. The damage caused by a strainburst may be exclusively related to the energy stored near the excavation or affected by the energy of an associated remote seismic event. If the damage is only related to the stored energy, the burst is self-initiated and the related seismic event is co-located as it is a result of the burst. Alternatively, if a remote seismic event triggers the burst, the rockburst is called a seismically triggered strainburst, the damage is only vaguely or unrelated to the dynamic stress change or the energy of the triggering event. If the damage is strongly influenced by the energy radiated from the remote seismic source, the burst is called a seismically triggered, dynamically loaded strainburst, and the damage is then also related to the dynamic stress change caused by the triggering event.

Because the source of energy differs in each of these cases, it is necessary to differentiate between these strainburst types when selecting rock support:

- for strainburst triggered by a remote seismic event, the damage is related to the stored energy alone and unrelated to the magnitude of the event; whereas

- for seismically triggered and dynamically loaded rockbursts, the damage is magnified by the seismic event and thus in part related to the magnitude of the remote seismic event adding damage causing energy.

\subsubsection{Seismically triggered strainburst}

If a meta-stable condition exists, a strainburst may be initiated by a further mining-induced change in local stress called mining-induced strainburst, or may be triggered by a remote seismic event called seismically triggered strainburst. In both cases, the stress conditions reach and exceed a limit-equilibrium state, i.e. the excavation is critically stressed or the static plus dynamic stress increment is high enough to bring the rock mass to failure. In this case, the severity of damage will depend on the stress level, the rock mass characteristics and the local mine stiffness. It is not or only vaguely related to the dynamic stress change and damage should not be related to the energy of the triggering event.

In other words, damage caused by a seismically triggered strainburst is caused by a sudden violent bulking of stress fractured rock largely due to static overloading. If well supported, no rock is ejected as all released energy is consumed by friction in the supported, broken rock. If the support fails to control the bulking, local signs of distress are observed (Figure 4). 


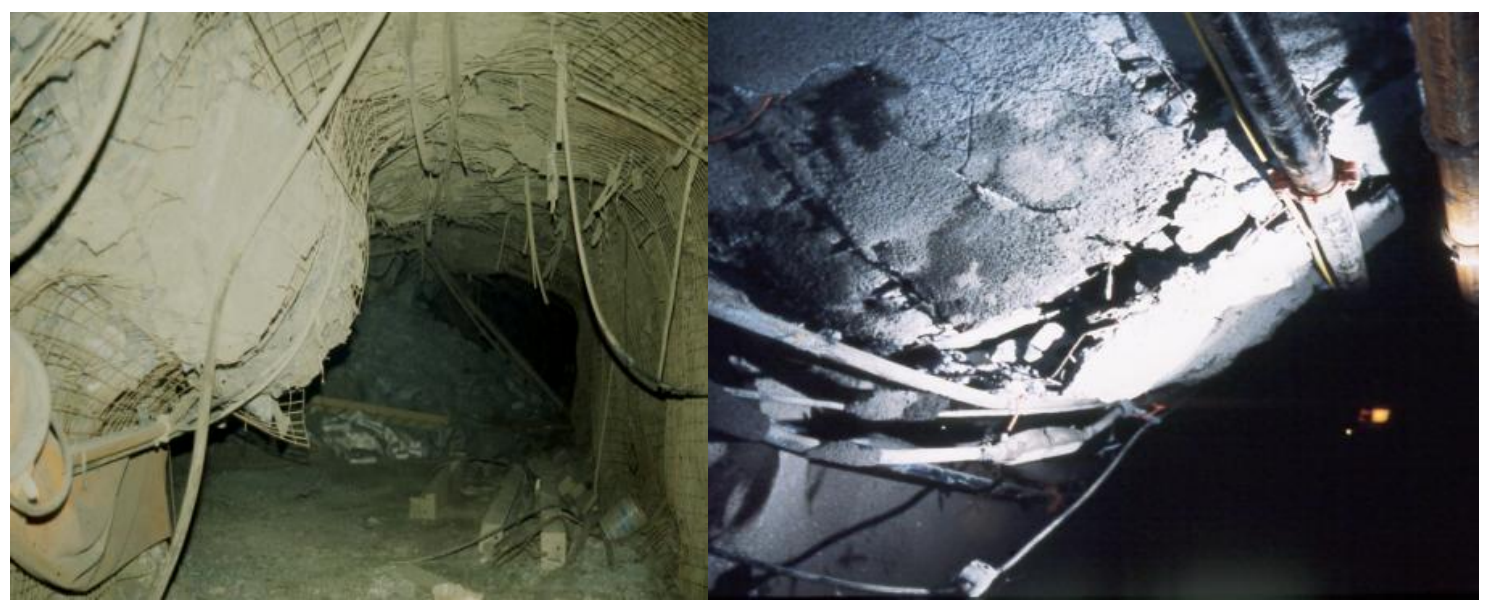

(a)

(b)

\section{Figure 4 Support system damaged by a seismically triggered strainburst causing loading by rock mass bulking:}

(a) supported by bolts and mesh; and (b) by bolts, mesh, and shotcrete (see case study; Section 8.1, 1996 CRBSHB (Kaiser et al., 1996)

The depth of failure of seismically triggered strainbursts can then be estimated based on the empirical Equation 1 and the related convergence by multiplying $d_{f}$ by the BF. However, it must be noted that Equation 1 was largely derived from damage records of a single tunnel or tunnels in a relatively stiff mining environment providing a limited stored energy pool. Therefore, much larger depth of failure would have to be expected in soft loading system environments, e.g. during late stage mining at a high extraction ratio. Furthermore, factors that increase the stored strain energy enhance the strainburst potential and affect the severity of damage.

\subsubsection{Dynamically loaded strainburst}

When a remote seismic event adds substantial dynamic stress to the failing rock, the seismic event not only triggers the strainburst but also adds energy to the damage process by deepening the failure zone and thus the related bulking deformation. During a dynamically loaded strainburst, the SL temporarily exceeds a critical stress level that would trigger a strainburst. In this case, the damage is in part related to the dynamic stress change or the energy of the triggering event.

The depth of failure of a dynamically loaded strainburst can then be estimated based on a modification of the empirical Equation 1 with the constants depending on the ground motion at the damage location. For specific assumptions, Kaiser (2006) showed that the constant $C_{1}$ depends on the level of dynamic stress increment due to a remote seismic event and found, supported by numerical modelling, that $C_{1}$ can be related to the induced ground motion (ppv) as presented in Table 2.

Because the safety margin, measured by the factor of safety (FoS), is defined as the ratio of capacity to demand, it follows that for a given capacity of a rock mass to hold stress, the difference in dynamic demand needed to cause damage must depend on stress level before dynamic loading. If the static stress level $S L=\sigma_{\max }$ UCSS is at the critical level, e.g. $S L_{o}=0.42$ for massive rock, any stress increment will trigger failure and the amount of deepening will depend on the amplitude of the dynamic stress pulse and is proportional to the dynamic change in SL. If the static SL is less than the critical level, no damage will occur until the SL (static plus dynamic stress) exceeds the critical $\mathrm{SL}_{\mathrm{o}}$. If $\mathrm{SL}$ is greater than the critical level, failure has already started, i.e. $d_{f}>0$, and any dynamic stress increment will deepen the failure zone. Because the dynamic $\mathrm{SL}$ change is small, unless a seismic event of high magnitude is close to the damage location, the dynamic deepening effect is often only a small percentage of the static depth of failure. An example is presented by Kaiser (2006) and illustrated by Figure 6.6 in Kaiser et al. (1996). 
Table 2 C1 for dynamic depth of failure determination; $C 2=\mathrm{SL}_{\circ} \mathrm{C}_{1}$ (Kaiser, 2006)

\begin{tabular}{ccc}
\hline $\operatorname{ppv}(\mathbf{m} / \mathbf{s})$ & $\mathbf{C 1}$ & Mean $\mathbf{S L}_{o}$ for $\mathbf{d}_{\mathbf{f}}=\mathbf{0}$ \\
\hline Static & 1.37 & 0.42 \\
0.5 & $1.54-1.74$ & 0.35 \\
1 & $1.79-2.08$ & 0.29 \\
2 & $2.17-2.86$ & 0.23 \\
3 & $2.63-3.64$ & 0.18 \\
\hline
\end{tabular}

In summary, a dynamically loaded strainburst is a sudden violent bulking of stress fractured rock due to static and dynamic overloading. The related convergence can be estimated by multiplying the combined depth of failure $d_{f(\text { stattdyn) }}$ by a representative bulking factor (BF). Rock ejection is only observed if not all released energy is consumed by the support system and by friction in the supported, broken rock.

\subsubsection{Role of local mine stiffness}

The concept of machine stiffness influencing the post-peak failure of rock in terms of strength drop and energy release has long been recognised and the concept is applicable in the field, where the failure of a pillar (rock mass) is affected by the mine stiffness (Figure 5).
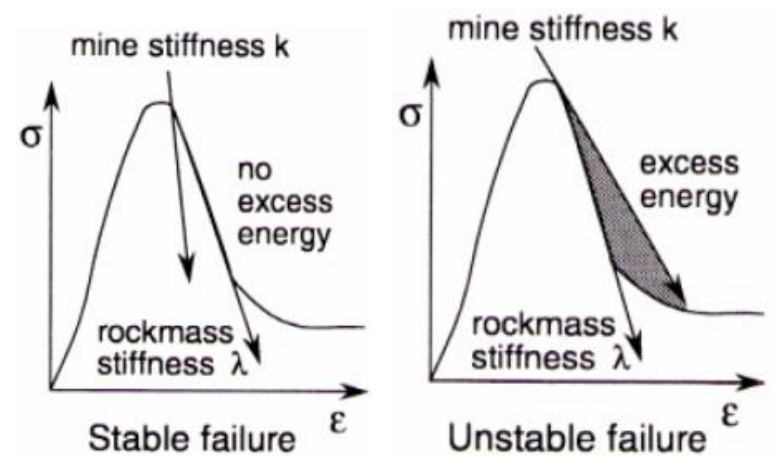

\section{Figure 5 Schematic illustration of system and mine stiffness concept - 1996 CRBSHB (Kaiser et al., 1996)}

For a pillar scenario, it is relatively simple to understand the mine stiffness concept (introduced by Salamon, 1970). The post peak slope $\lambda$ of the stress-strain or load-displacement relationship of the rock mass is defined by the ratio of post failure deformation (strain) to load (stress) drop. The latter is affected by the pre-failure stress level, and the former by the deformation (strain) increment that occurs during failure. This deformation (strain) is only in part affected by the rock mass properties (e.g. Young's modulus). It is strongly influenced by geometric factors such as the excavation spans on either side of a (rib) pillar. The post-peak deformation therefore generally increases with increasing extraction ratio, and the burst or damage potential increases as the potential for larger, e.g. hanging wall to footwall deformations increases. This is reflected by the often quoted statement, "without deformation potential there is little burst potential." (W. Blake, pers. comm., 2013).

For a single opening, i.e. a fixed geometry, the stress level is given by the tangential stress near the excavation and the post-peak deformation is controlled by the tangential strain. Any factor that increases the post-failure convergence therefore renders an excavation more prone to (strain-) burst damage. For a given stress level, the following factors affect the local system stiffness, the post-failure convergence and thus the burst severity in stress-driven failure modes:

- Dynamic depth of failure: 
- a short, very shallow spall will be deformed less than a larger, deep spalling slab (observed as spitting versus ejection).

- Geometric geology factors:

- a damage zone reaching a weak geological structure will be deformed more than an equal damage zone in massive ground,

- a damage zone near a stiff geological heterogeneity (dyke) will be deformed differently when entering than when exiting the heterogeneity, typically causing face bursting when entering dykes, and wall or roof bursting when exiting dykes.

- Excavation shape or size changes:

- larger excavations generally are more burst-prone because the deformation is scaledependent (the elastic stress is not),

- shape changes influence both the deformation and the stress, rendering locations with geometry changes more burst-prone.

It follows that the excavation vulnerability for strainbursting should be influenced by these factors. Only some have been captured by the excavation vulnerability index introduced by Heal et al. (2006). Unfortunately, the deformation response of an excavation is typically ignored when assessing the damage potential or interpreting damage severity. Furthermore, in the authors' opinion, burst indices that focus entirely on intact rock properties are doomed to fail in predicting burst potential because the dominant driving factor, i.e. the local system stiffness or deformation potential, cannot be measured by such parameters. The burst potential and severity is a function of factors that influence the local mine stiffness.

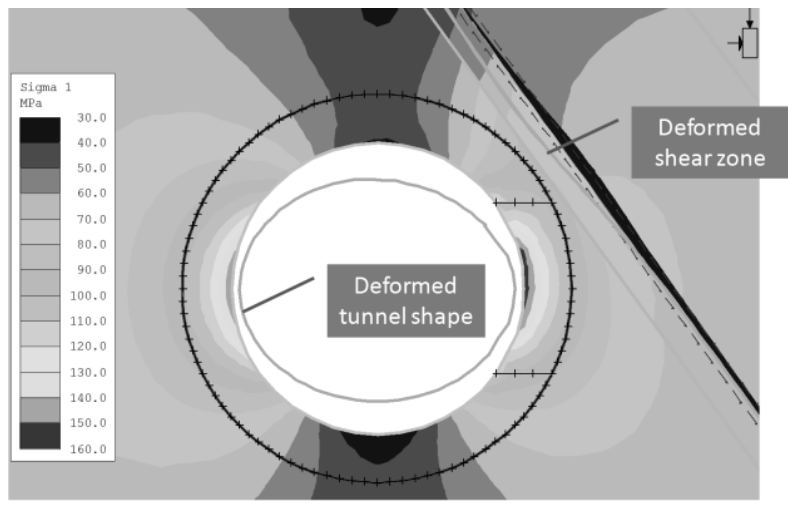

(a)

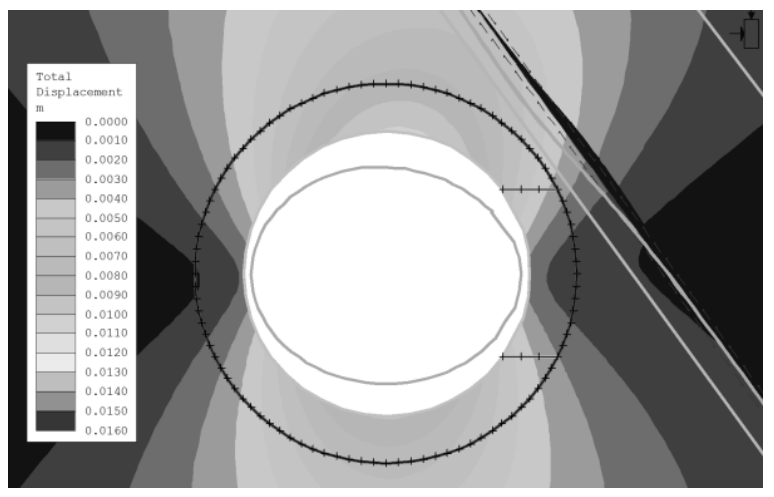

(b)

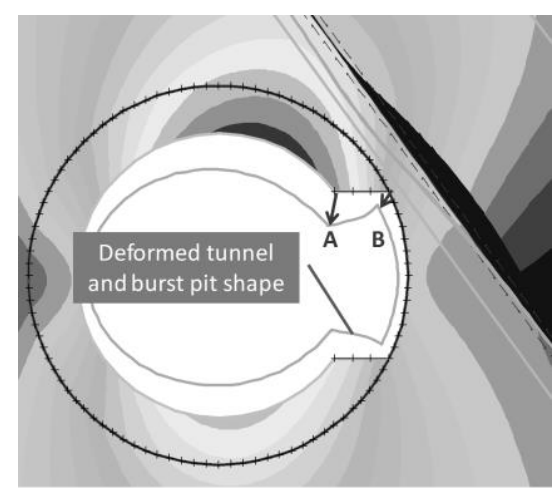

(c)

Figure 6 Schematic model of a $6 \mathrm{~m}$ wide circular tunnel to illustrate elevated strainburst potential due to tunnel parallel shear zones: (a) major principal stress contours together with shear slip directions and deformed shape of tunnel and shear (grey); (b) total displacement due to tunnel excavation with slight 


\section{non-symmetry in displacement field due to yielding structure (shear displacement magnitude in black); and (c) total displacement after removal of a block of ground on right wall (simulating excavation by strainburst)}

Understanding this concept is most important for civil construction, for example, when tunnelling with tunnel boring machines (TBM), where the excavation geometry is essentially constant. For a given design domain, with constant stress and rock mechanical properties, the strainburst potentials should be constant unless the deformation potential varies. In such a domain, no bursting or continuous bursting would be anticipated, which is rarely the case. In the authors' opinion, local system stiffness variability is the predominant cause for variability in burst frequency and damage severity in otherwise uniform conditions. Of the factors listed previously, geometric geology factors, weak geological structure or stiff dykes have the most effect on the deformation variability and thus on the variability in strainburst potential. This is illustrated by the schematic modelling results presented in Figure 6 and then by the images presented in Figure 8 from the Jinping-II hydro-power project tunnel in China (unpublished data, courtesy of Dr Xia-Ting Feng (2011) of the State Key Laboratory of Geomechanics and Geotechnical Engineering, Wuhan, China; presented at International Colloquium on Progress and Challenges in Rock Mechanics, Hangzhou, China).

The major principal stresses shown in Figure 6(a) are slightly non-symmetric due to a yielding shear zone dipping at $45^{\circ}$ to the right of the tunnel. The maximum stress on the right is about $10 \mathrm{MPa}$ higher than that on the left and the volume of stressed rock (e.g. > $100 \mathrm{MPa}$ ) is also higher. This is caused by slippage on the shear zone (indicated by two arrows; magnitude of slip shown in black). The resulting tunnel convergence (shown in grey) is also slightly non symmetric (larger on the side of the shear).

The total displacements shown in Figure 6(b) after excavation, corresponding to Figure 6(a) also show a slight non-symmetry with larger and deeper deformations on the side of the shear zone. The total displacement pattern after a segment of the highest stressed rock on the shear zone side of the tunnel was excavated to mimic rockburst damage (Figure 6(c)). The shape was arbitrarily assumed to be $1 \mathrm{~m}$ deep, simulating a depth of failure $d_{f} / a$ of 0.33 that corresponds to a SL of 0.67 . As a result of simulated 'burstrelated' slip on the shear, the convergence pattern becomes highly non-symmetric with the maximum deformation almost doubling on the near shear side of the burst. Since the deformations on the side of the shear are larger before a burst is initiated, the right side is more burst-prone. Once failure is initiated, the right side which is near the shear is in a softer loading system and thus is more prone to damage. The post burst deformation on the excavated volume of rock is highlighted by the two arrows, showing a change in magnitude and orientation along the upper edge of the excavated segment from Points $A$ to $B$ (arrows). Accordingly, the loading system stiffness is lower near $A$ than at $B$. This is illustrated by Figure 7 for a rock with a brittle load-displacement characteristic. Nevertheless, due to the decrease in deformation demand from $A$ to $B$, the burst damage might arrest itself. This might occur before the shear is reached if the postpeak stiffness becomes higher than the post-peak failure slope of the rock (Figure 7).

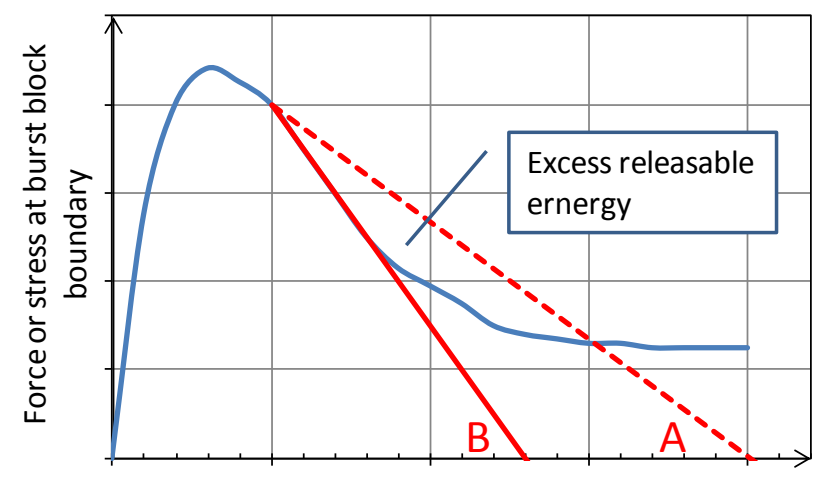

Displacement at edge of burst block

Figure 7 Force-displacement graph for a brittle rock element at the burst front together with the liberalised system stiffness (deformation path during failure) for Point 


\section{A at the excavation boundary and for Point $B$ at the outer edge of the burst segment (shown in Figure 6(c))}

This schematic model illustrates the process of mine stiffness modification due to geological structures near an excavation. There is ample qualitative field evidence supporting this concept and interpretation. Two examples from the Jinping-II tunnels are presented in Figure 8.

Figure 8(a) presents a case where two factors combine to enhance the burst potential: (1) geological structures that create a potential for movement (joint J18), and (2) a nearby, in-filled (1 to $10 \mathrm{~mm}$ ), continuous shear zone with increased joint frequency on either side. Both change the local system stiffness and the former creates a weakness; both enhancing the burst potential. The combination of these two factors is interpreted as being the cause for a localised strainburst with a volume of $6.3 \mathrm{~m}^{3}$.

A second, most interesting, situation has been captured by a detailed microseismic monitoring program producing the microseismic source locations shown in Figure 8(b). Assuming that the source locations shown in this figure are accurate, and not an artefact of sensor array geometry, the data suggest that a geological structure is activated ahead of the tunnel and that, as a consequence of the enhanced deformation or softening of the system on the right side of the tunnel, a high density of seismic events was recorded at the location where deformations due to the advancing face intersecting the shear would be the highest. The mine stiffness in this area is lower due to the deformation enhancing effect of the activated shear ahead of the tunnel. 


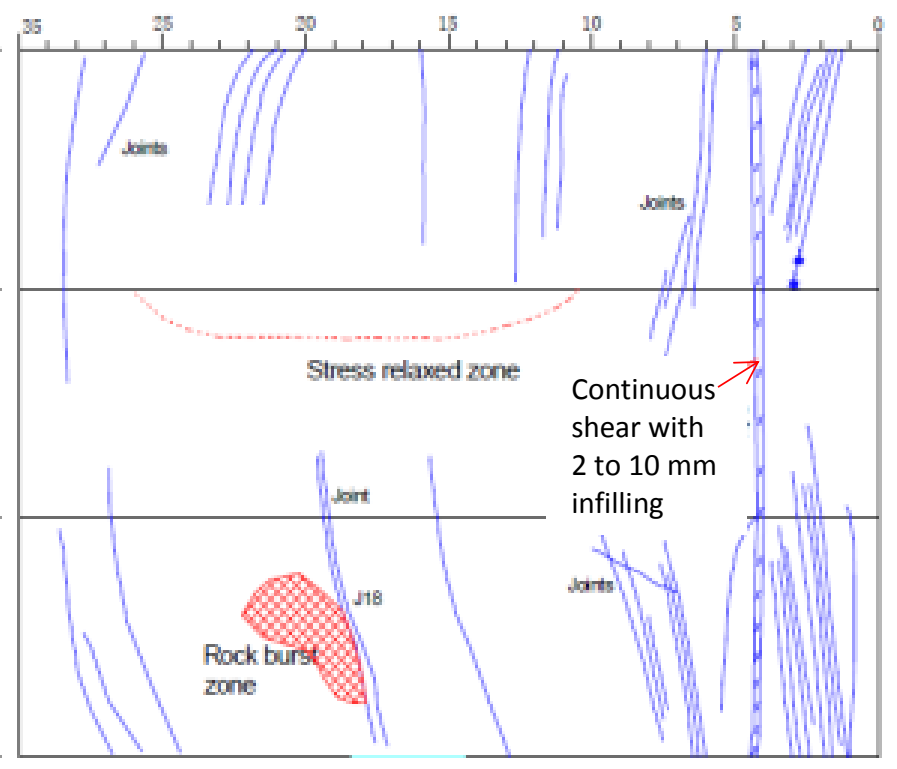

(a)

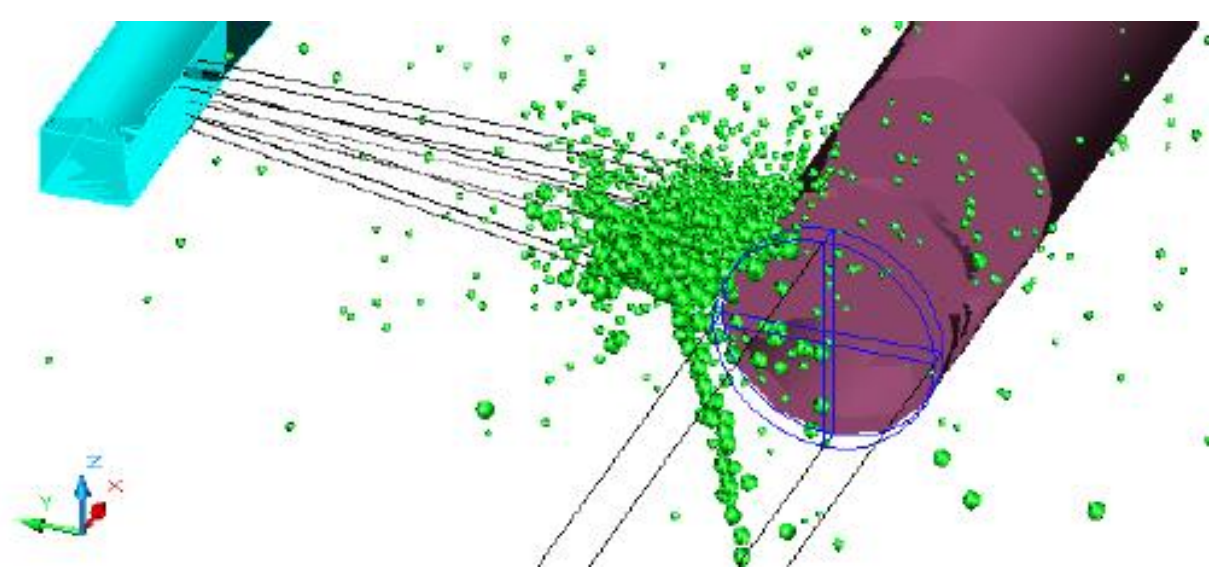

(b)

Figure 8 (a) Unfolded section with rockburst location with geological structures and with images of wall damage near structure (9 January 2010; volume of burst rock $6.3 \mathrm{~m}^{3}$ (Feng, pers. comm., 2011)); and (b) seismic source locations near tunnel face in the third headrace (Feng, pers. comm., 2011)

A further example is illustrated by Figure 9 on data obtained from Amann and Thöny (pers. comm., 2013). While this tunnel is shallow and not in burst-prone material, it nicely shows the effect of a geological structure (a major fault in this case) on the convergence profile and by implication on the loading system stiffness. At Location 1, the system is stiff and there is little deformation with tunnel advance but, at Location 2, the system is relatively soft, with 6 to 7 times more radial deformation and thus more tangential strain.

The resulting effect is schematically illustrated by Figure 9(c), assuming that the rock at both locations exceeded its load bearing capacity before the start of deformation measurement. For the given rock mass failure characteristics, there would be little decrease in loading system stiffness at Location 1 as the tunnel advances, whereas at Location 2 there would be a much larger softening with a related increase in releasable energy. 

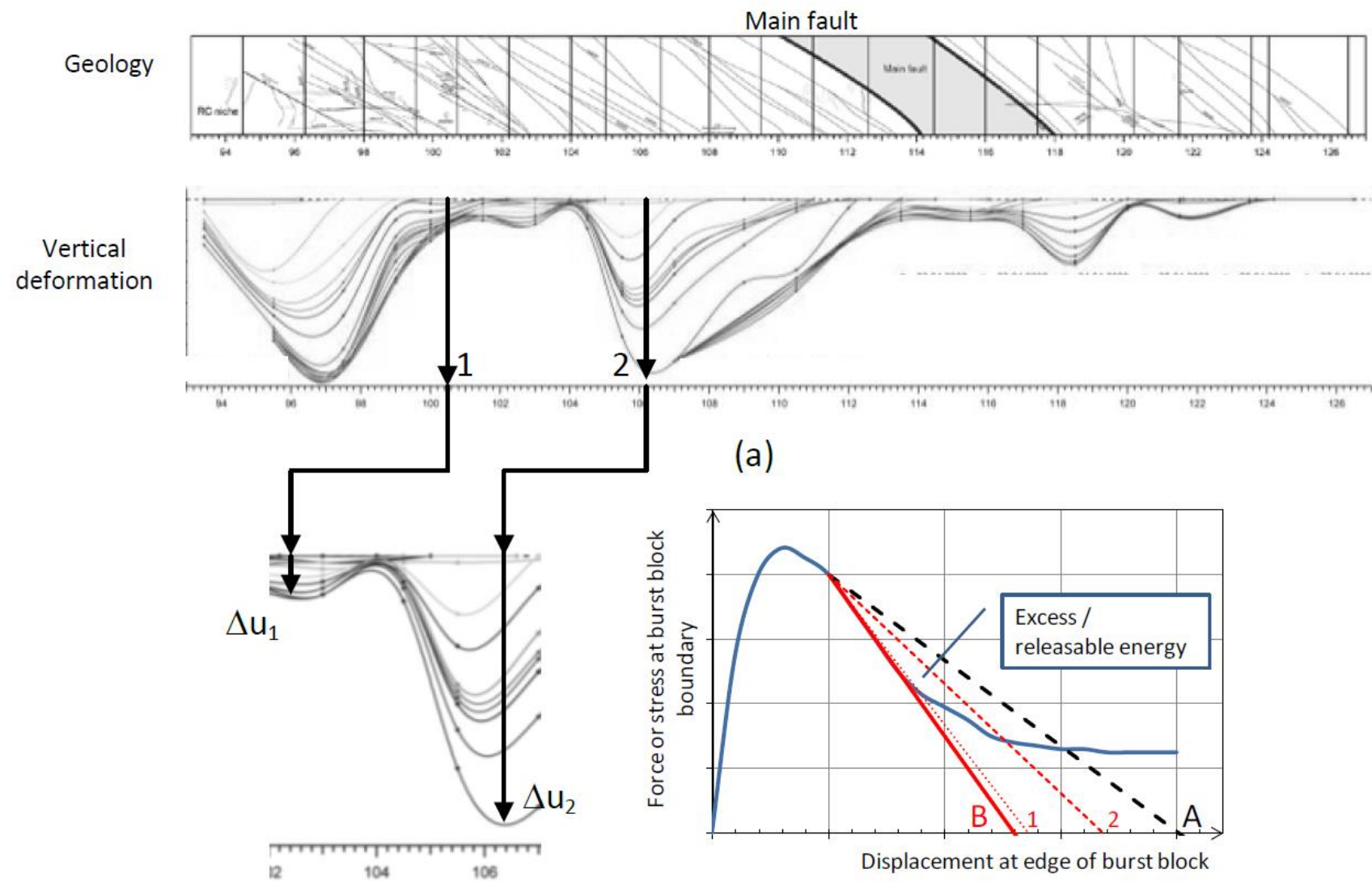

(b)

(c)

Figure 9 Deformation measurements along tunnel before entering a major fault zone: (a)

Time dependent evolution of deformation with tunnel advance (first peak is related to nearby niche geometry, second peak near $106 \mathrm{~m}$ is related to upcoming fault); (b) close-up of deformation evolution with advance (Time); and (c) illustration of time dependent or advance - related softening of loading system (small change at Point 1, larger change at Point 2) causing elevated excess energy release potential at Point 2 (modified after Amann and Thöny, pers. comm., 2013)

As indicated previously 'without deformation potential there is little burst potential'. These case examples and the schematic model suggest that the most important or controlling factor for strainbursting is the local mine stiffness and that this stiffness is strongly influenced by deformation modifiers such as geological structure and excavation geometry changes. Much more effort is required to establish means for early detection of potential changes in local mine stiffness due to such deformation modifiers. 


\section{$4 \quad$ Engineering principles for support design}

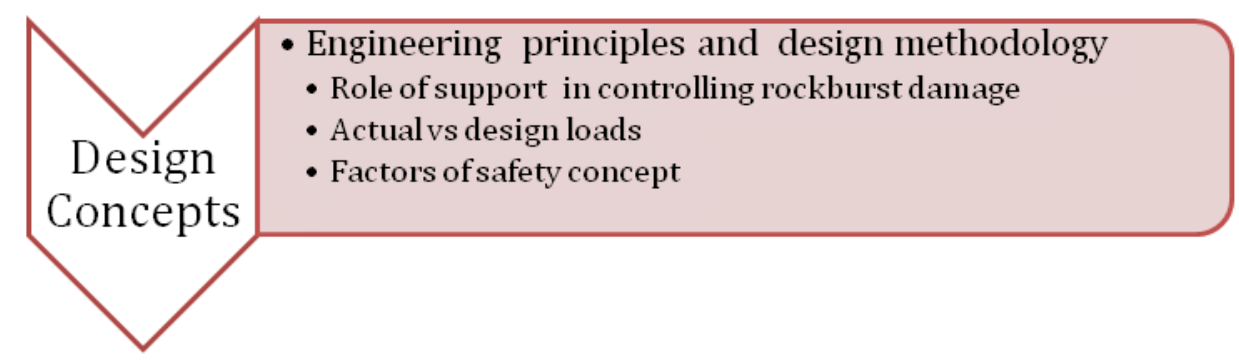

Geotechnical or geomechanics engineering entails several fundamental principles: identification of relevant failure mechanisms; definition of design loads, events and magnitudes; and determination of an acceptable safety margin.

\subsection{Relevant failure mechanisms}

In burst-prone ground, three distinct mechanisms are involved in causing damage during rockbursts. In order of priority or frequency of occurrence, these mechanisms are:

- Sudden volume expansion or violent bulking of the rock mass near an excavation due to stressdriven fracturing. The significance of this bulking process is often not recognised even though it is now evident that it accounts for a substantial number if not the majority of damage observed in rockbursts,

- Rockfalls (or falls of ground), seismically triggered or dynamically loaded by seismic shaking, constitute the second most common type of damage in burst-prone mines,

- Ejection of rock caused by one of two fundamentally different processes: (1) momentum transfer between blocks of rock of differing size, and (2) wave energy transfer from large remote seismic events to fractured rock near a stressed excavation.

Identification of the predominant rockburst damage mechanisms therefore forms a fundamental basis for support design. Each mechanism is to be considered separately or in combination when selecting support, as the drivers and the consequences may differ. The first is driven by excessive stress, the second by failure or acceleration of relaxed ground, and the third by stress wave action.

\subsection{Overview of rockburst support design process}

The goal of support in burst-prone ground is to mitigate the potential consequences of a rockburst, e.g. to create a safe workplace preventing injuries and fatalities to workers and damage to openings and mining equipment. For this purpose support is designed to meet load, displacement and energy demands with appropriate support capacities, under anticipated static and seismic loading as well as given ground and excavation conditions. The workflow of a rational design process is presented in the CRBSHB. It consists of the following components: obtaining design inputs, zoning into design domains, and evaluating support demands and capacity for support system selection.

As in all engineering, the safety margin or risk of failure is assessed and measured by either a FoS or a probability of failure. For support design, three FoSs are to be assessed, i.e. the load, displacement, and energy factors of safety:

$$
F S_{\text {Load }}=\frac{\text { Support Load Capacity }}{\text { Load Demand }} ; F S_{\text {Disp }}=\frac{\text { Support Displacement Capacity }}{\text { Displacement Demand }} ; F S_{\text {Energy }}=\frac{\text { Support Energy Capacity }}{\text { Energy Demand }}
$$

The load demand is controlled by the geometry of a failure rock volume, the displacement demand by the depth of failure and the rock mass bulking factor, and the energy demand by the volume of ejected rock and a representative ejection velocity. 
The support selection for rockburst conditions is then based on the load-displacement characteristics of each individual support component and the support system, consisting of compatible support elements to provide the desired functions.

\subsection{Role of support}

Support in burst-prone ground has to create a safe working environment under both static and dynamic loading conditions by providing four functions as illustrated by the examples in Figure 10:

- Retain broken, fractured rock, e.g. mesh, shotcrete, spray-on liners, etc.,

- Reinforce marginally stable rock mass, e.g. rebar, stiff friction bolts, etc.,

- Hold retaining system and reinforced rock back to stable ground with deformation compatible support components, e.g. deformable cables, yielding bolts, etc.,

- Connect holding and retaining components to ensure system stability, e.g. using straps, large plates, strong threads and compatible plates (hole size), etc. Weak links in a rock support system must be eliminated.

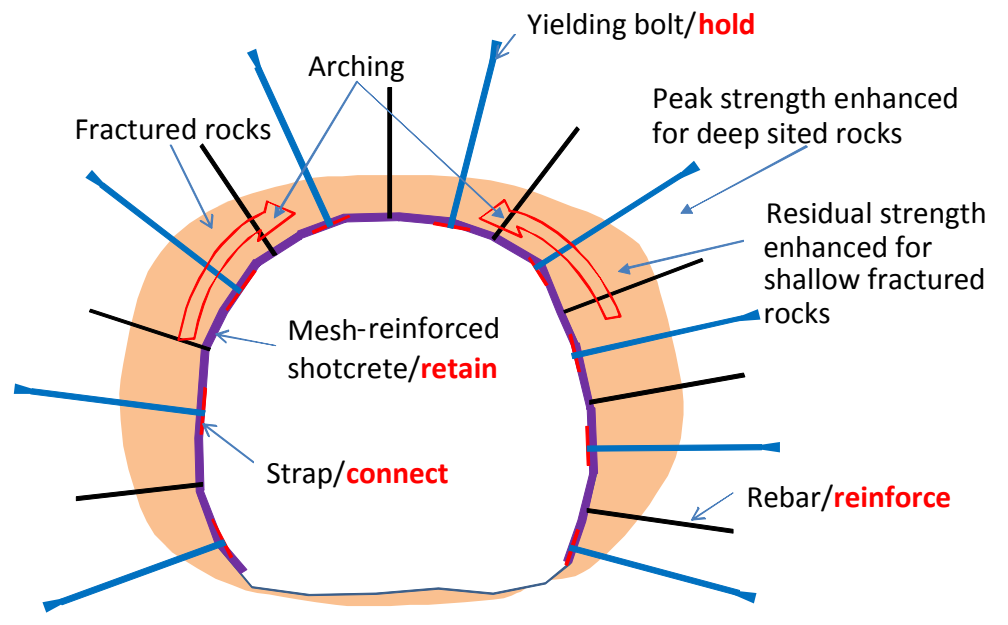

Figure 10 Four functions required to provide a reliable support system for burstprone ground: retain, reinforce, hold, and connect (Cai and Kaiser, 2013)

\section{$5 \quad$ Assessment of rockburst damage potential}

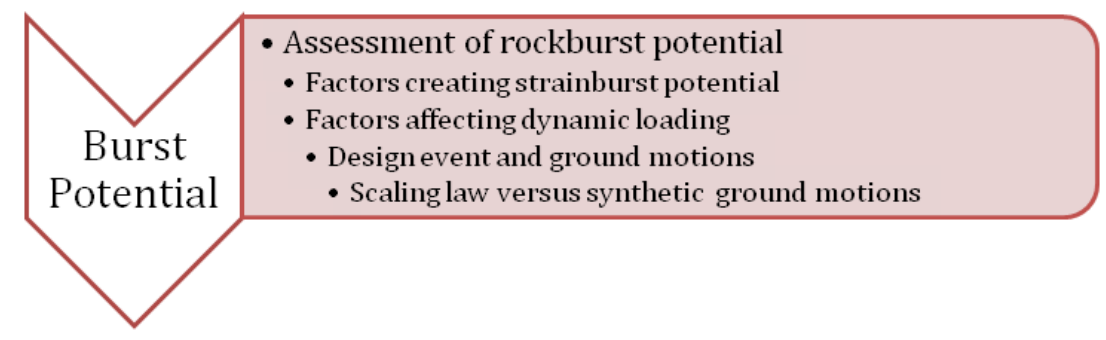

Factors affecting strainburst potential and excavation vulnerability have been discussed in previous sections. In the following, the focus is on those aspects that enhance the burst potential by adding dynamic loads, deformations or energy. Such dynamic effects are related to the ground motions generated by a remote seismic event. Radiating waves may cause stress pulses, accelerate or eject rock. Hence, for damage potential assessment and support design, it is necessary to identify meaningful assumptions to determine anticipated ground motions (called actual ground motions, e.g. ppv) and to determine ground motions that should be used for design (called design ground motions, e.g. ppv $v_{D}$ ). As will be discussed next, they are not the same. 


\subsection{Ground motions}

\subsubsection{Seismic hazard}

A hazard is any agent or source that is reasonably likely to cause harm or damage to life, health, property, or the environment in the absence of its control. In other words, a hazard is a situation that poses a level of threat to life, health, property, or the environment. In earthquake engineering, seismic hazard assessment is the study of expected earthquake ground motions at any point on the earth. Seismic hazard maps are built to display earthquake ground motions for various probability levels across a region and are applied in seismic provisions of building codes, insurance rate structures, risk assessments, and other public policy. As an example, the 2010 updated Canadian national seismic hazard map presents contours of spectral acceleration that should be anticipated for a period of 0.2 seconds. This hazard map does not present contours of actual measurements but shows accelerations that should be anticipated at a probability of $2 \%$ over 50 years; they are ground motions intended for use in design. Hence, a seismic hazard is defined for engineering design based on observations of extreme conditions in a given time window (see scaling laws; Section 5.1.4).

Unfortunately, it is not possible to establish such permanent hazard maps in mining. Conditions change and the design basis has to be adjusted for mining-induced seismicity patterns. Hence, it is meaningful to establish a design event or a volume of rock containing a design event for each design domain.

\subsubsection{Definition of design event and magnitudes}

For starters, it has to be recognised that design parameters are seldom, only at the extreme, equal to measurements. In many engineering disciplines, engineering standards define design approaches and assumptions, e.g. in civil engineering, regional earthquake loads (accelerations), hundred-year snow or wind loads, flood levels etc., are specified as a basis for design. By analogue, for burst support design, it is necessary to define a design 'event', in terms of possible, but not actual, static and dynamic stress levels and gravity enhancing ground accelerations from seismically induced ground motions and rock failure. As there are no engineering standards to define the design event or magnitude for mining, the CRBSHB provides a systematic approach to establish design controlling drivers of failure, e.g. $\mathrm{ppv}_{\mathrm{D}}$ based on scaling laws.

Scaling laws, used for design purposes, are often criticised for reasons largely founded in miscommunication. As explained above, design assumptions are seldom congruent with actual observations. Hence, measured ground motion patterns should not be congruent with those assumed for design. Many critiques of the use of scaling laws, for example, which is founded in a lack of understanding of the above described engineering design approach, is unfounded. Design assumptions are used to describe possible outcomes, outcomes that do not necessarily reflect the actual measurements.

In this design approach, the dynamic demand for support design is, as in the CRBSHB, based on source related ground motions, e.g. ppv $v_{D}$ linked to ejection velocity and then to energy demand. In situations of applicability, constrained by the arguments presented above, the ground motions are then obtained from scaling laws, relating the size (magnitude, or moment, or energy) and location of a seismic event to the extreme ground motions possible at some distance from the event.

Thus, while seismic slip sources radiate focused waves, due to uncertainties in source orientation, sequencing of mine extraction, and other factors, it is prudent to assume that such detail is not available for support design or may change over time. Hence, it is appropriate to assume that equally critical design ground motions should be expected at a given distance from a source independent of the direction of slip for engineering design purposes. Ground motions obtained from a scaling law therefore serve as design inputs and should never be used to predict actual ground motions or to compare directly with specific field observations. For a given event, the scaling law with applicable parameters, however, should always provide an upper bound value to field observations. At the limit, scaling laws must be consistent with available data from a seismically active mine or a seismically active domain in a mine. 


\subsubsection{Ground motions from fault-slip events}

As is elaborated above, the spatial distributions of ground motions due to a specific seismic event in a mine differ in reality from those needed for design. The latter, called design $\mathrm{ppv}_{\mathrm{D}}$, is required for rockburst support design. For this purpose, it is necessary to anticipate the maximum possible ground motion at a given point in a mine from a defined design event (DE) with a design magnitude (DM), in a given volume of rock (DV) or at a specific location $(\mathrm{DV}=0)^{[5]}$.

\subsubsection{Seismic wave propagation in rock}

Seismic wave propagation and ground motion patterns in heterogeneous rock masses and mines with multiple excavations are complex and local site effects may cause drastic spatial variations in ground motions and thus damage severity to openings.

A complete quantitative understanding of ground motion in underground mines requires a simultaneous consideration of seismic event mechanism, 3D effects of the rockburst source, wave propagation paths, local site conditions, in situ and mining-induced stresses, and much more. It requires detailed information of geological structure and geometric constraints. Hence, it is next to impossible to estimate the actual ground motions, even if the source mechanism of a design event was properly defined and the event location correctly located.

Due to focused radiation patterns from fault-slip events, the actual ground motions at a particular location ranges from zero to a maximum depending on the slip direction of the source. Figure 11 shows the radiation patterns for a point source slipping on a vertical fault. The $p$-wave radiates faster than the s-wave with maximum ground motions at $45^{\circ}$ to each other. The $p$-wave and s-wave maxima are at $45 / 135^{\circ}$ and $0 / 90^{\circ}$ to the slip direction, respectively. Alternatively, it can be seen from this figure that there will be zero compressive ppv in the slip direction (vertical) and perpendicular to it (horizontal), and zero shear ppv at $45^{\circ}$ to the slip direction.

For a horizontal tunnel located at a distance $y$ above this source, the maximum $p$-wave ppv or ppa would be expected at Points $A$ and $A^{\prime}$ and the maximum s-wave ppv or ppa at Point $B$. The ground motion distribution along this tunnel is illustrated by Figure 12 for a set of parameters given in the figure legend and for two cases: (1) with a vertical slip direction $\left(\beta=0^{\circ}\right)$, and (2) with a source inclined at an angle $\beta=25^{\circ}$ from vertical.

Also shown in Figure 12 is the envelope fitted to the maximum ground motion $\left(\mathrm{ppv}_{\mathrm{s}}\right)$ for all source orientations $\beta=0 \pm 45^{\circ}$. This envelope constitutes the upper bound to all possible peak ground motions for a single source of a given magnitude, moment, or energy (magnitude used here). It provides the design ppv $v_{D}$.

$\mathrm{ppv}_{\mathrm{D}}=$ design ground motion; $\mathrm{DE}=$ design event chosen for a given design domain with $\mathrm{DM}=$ design magnitude (or other measure of event intensity; seismic energy or moment) in a specified DV = design volume, the volume of rock that might host the DE; it may be zero if a design is aimed at a single design event at a specific location, then $D V=0$. 


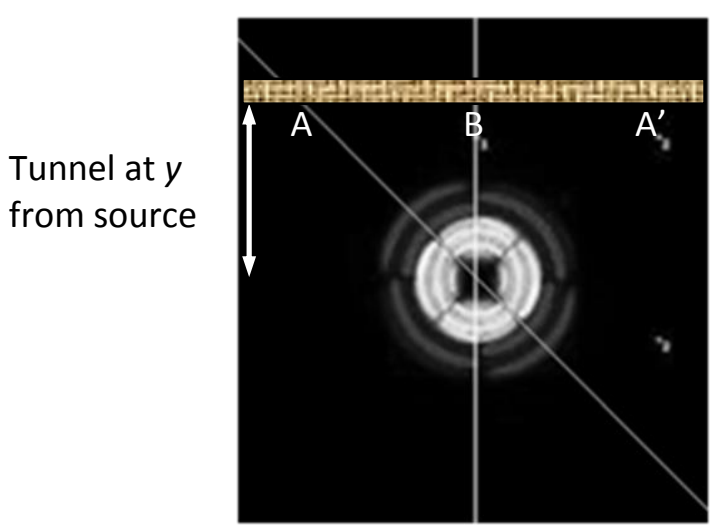

Figure 11 Radiation pattern for a seismic point source slipping on a vertical fault: $p$ wave contours are shown in dark grey (for opposite polarities), and s-wave contours are shown in light grey

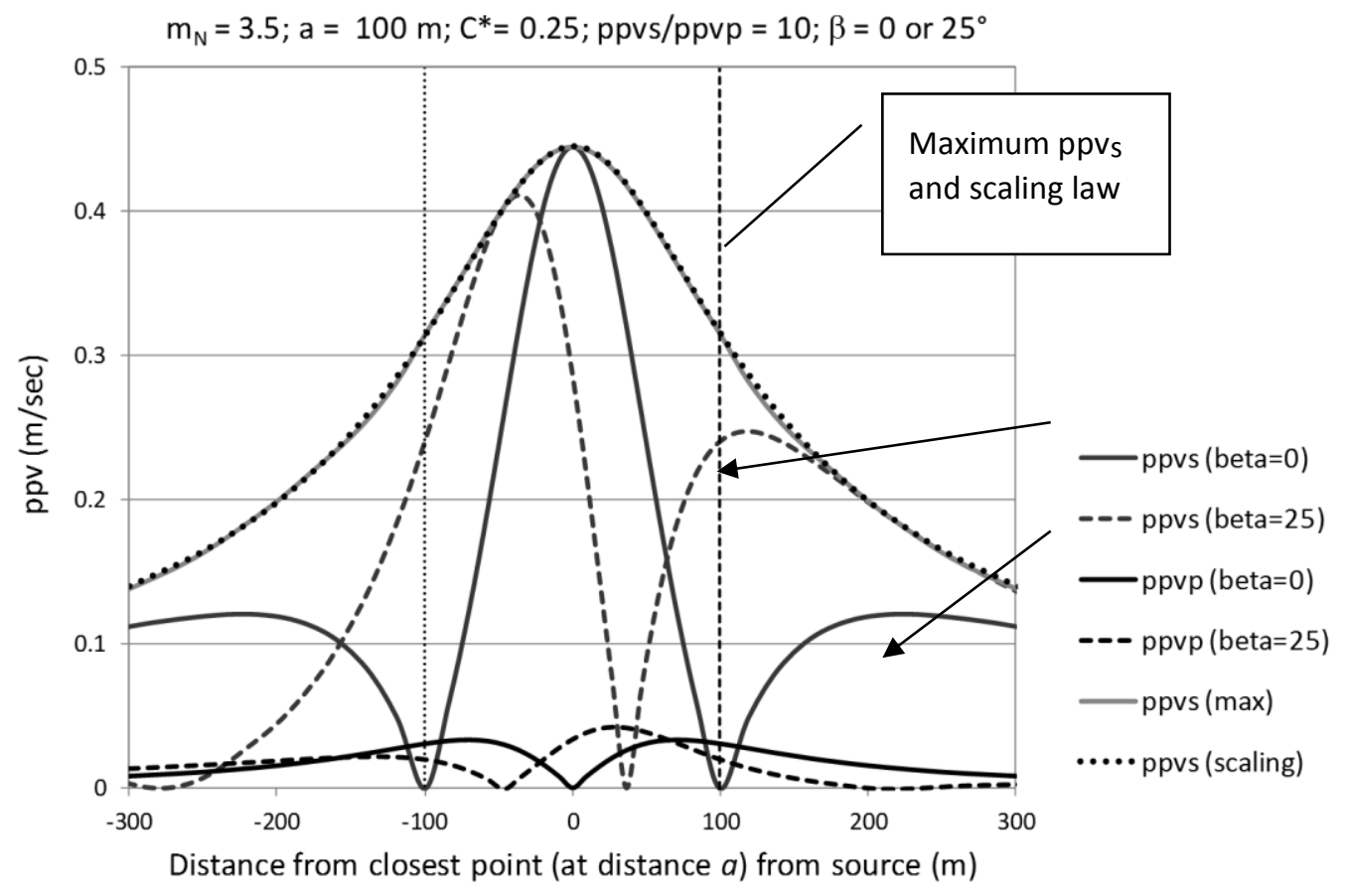

Figure 12 Ground motion distribution for shear wave $\left(\mathrm{ppv}_{\mathrm{s}}\right)$ along tunnel with a seismic source at $y=-100 \mathrm{~m}$ below the tunnel (Cai and Kaiser, 2013)

\subsubsection{Scaling law for use in support design}

For engineering design, the fault slip direction is often unknown or highly variable and less predictable than event magnitude and location. Thus, for design purposes, it is prudent to assume that the source is always oriented in the worst possible direction and thus that extreme s-wave ground motions are to be experienced at locations along an excavation; a tunnel in the above illustrated case. The ground motion corresponding with the entire spectrum of source directions is shown in Figure 12 as ppv $(\max )$. The resulting upper limit radiation pattern of the highest possible ground motion $\mathrm{ppv}_{s}(\mathrm{max})$ is spherical and the magnitude relates to the distance from the source in an inverse manner $(1 / R)$. Thus, the maximum ground motion presented in Figure 12 can be predicted with a scaling law ppvs (scaling) of the form presented in Equation 5. It is superimposed as a dotted line in Figure 12.

In other words, the scaling law presented below provides a design ground motion $p p v_{D}$ that differs from the actual ground motion. For the example shown in Figure 12, only at the point closest to the source is the design ground motion ppv $=0.44 \mathrm{~m} / \mathrm{s}$ identical to the actual ground motion, and only if the slip direction is 
perpendicular to the tunnel. At all other locations, the actual $p p v$ is less than the $p p v_{D}$ but the local possible maximum can be anticipated by the scaling law. For example, at $x= \pm 100 \mathrm{~m}$ from the point closest to the source, the $p p v_{D}$ would be about $0.31 \mathrm{~m} / \mathrm{s}$, while the actual $p p v$ values would be 0 and about $0.24 \mathrm{~m} / \mathrm{s}$ if the source was slipping perpendicular or at $25^{\circ}$ to the vertical, respectively. These values are of little engineering interest as they do not reflect possible upper bound conditions.

For this reason, it is meaningful to use a simple, but not simpler, means for the determination of the $p p v_{D}$, i.e. to estimate the ground motion for design with a design scaling law.

As indicated previously, these ground motion $\left(\mathrm{ppv}_{\mathrm{D}}\right)$ should not be expected to correspond with those measured in situ from one particular event, but measured ground motions should not exceed those predicted by scaling laws. As will be discussed in the section on forensics, ground motions from scaling laws cannot be used for forensic analyses of observed rockburst damage.

\subsubsection{Design scaling law to obtain $p p v_{D}$}

A scaling law provides the $\mathrm{ppv}_{\mathrm{D}}$ as a function of the distance $R$ from the source for a seismic event of defined intensity, which can be expressed by its seismic moment or event magnitude. The scaling law approach for $p p v_{D}$ estimation is a semi-empirical approach that does assume that the ground is isotropic and not dominated by internal boundaries causing strong reflections. In addition, the seismic source is simplified as a point source with no preferred radiation orientations for reasons explained previously. The scaling law approach should therefore not be compared with blasting as the frequency contents and wave nature (mostly $p$ - rather than s-wave content) do not compare.

\subsubsection{Far-field ground motion}

McGarr (1984) proposed the following scaling law:

$$
\log (R \cdot p p v)=-4.78+0.44 \log M_{0}
$$

Where $M_{0}$ is the seismic moment in GN.m, $R$ is the source-target distance in $\mathrm{m}$, and $p p v$ is in $\mathrm{m} / \mathrm{s}$. The scaling law in term of ppv then is:

$$
p p v=C^{*} \frac{M_{0}^{a^{*}}}{R},
$$

Where $a^{*}$ and $C^{*}$ are empirical constants (CRBSHB). These constants may vary between mine sites, however, based on the analysis of seismic data from a global database, it was found that $a^{*}$ can be fixed for many mines at $a^{*}=0.5$. The $C^{*}$ value can be determined from log $(R \cdot p p v)$ versus $\log \left(M_{0} \Delta \sigma\right)$ plots with upper-bound limits defined by the desired confidence, e.g. 90 or $95 \%$ confidence. These constants depend on ground conditions, mining method and related stress levels, mining and back fill sequences, as well as other factors influencing the seismic hazard.

Combining the above equations with semi-empirical relationships between seismic moment and magnitudes, the following equations for $\mathrm{ppv}_{D}$ based on seismic event magnitudes ( $m_{N}-$ Nuttli scale; $m_{L}-$ Richter scale or local scale) were established (1996 CRBSHB):

$$
\begin{aligned}
& p p v=C^{*} \frac{\sqrt{10^{\left(m_{N}+(1 \pm 0.15)\right)}}}{R} \\
& p p v=C^{*} \frac{\sqrt{10^{\left(m_{L}+(1.5 \pm 0.15)\right)}}}{R} .
\end{aligned}
$$

This design scaling law should only be applied to openings in the far-field, i.e. at distances greater than $R_{\min }$ from the seismic source (Kaiser and Maloney, 1997): 


$$
R_{\min } \approx 1.5\left(\frac{M_{0}}{\Delta \sigma}\right)^{1 / 3}
$$

Where $\Delta \sigma$ is the stress drop. Therefore, for typical mining-induced seismic events ranging from $\mathrm{m}_{N}=1.5$ to 4.0, the design scaling laws should not be applied to locations closer than 10 to $70 \mathrm{~m}$ for a stress drop of $1 \mathrm{MPa}$, and 5 to $30 \mathrm{~m}$ for a stress drop of $10 \mathrm{MPa}$. Near-field ground motions cannot be obtained by the above quoted scaling laws.

\subsubsection{Seismic hazard maps for support design}

For support design purposes, mine specific seismic hazard maps must be created based on the scaling laws. There are two options: (1) assuming a given design event at a defined location, or (2) assuming a design event in a defined volume of rock that could contain such a design event.

\subsubsection{Option 1: Seismic hazard maps for single design event (DE)}

This approach is followed when a single damage-causing source is anticipated, e.g. when a dyke is known to create a defined event at a defined location. It answers the question 'what support would be needed to survive this event?' It is most useful when rehabilitating support is to survive a future event of identical nature. The following steps are executed:

- Step 1: Define the maximum expected magnitude of the design event for an acceptable probability of occurrence or a desired confidence level.

- Step 2: Verify the constant $C^{*}$ for the scaling law or calibrate $C^{*}$ by plotting log (R.ppv) versus log $\left(M_{0} \Delta \sigma\right)(\mathrm{CRBSHB})$.

- Step 3: Use scaling law to define ground motion at support design locations.

This approach should not be followed in forensic analyses even if the design event is replaced by the actual damage-causing event. The actual ground motions differ from those obtained by the scaling law.

\subsubsection{Option 2: Seismic hazard maps for design events with uncertain event location}

This approach is followed when a volume of ground can be defined within which a damage-causing source is anticipated, e.g. when long-term seismic records permit a statistical analysis. It answers the question 'what support would be needed to survive an event of uncertain location but with a defined magnitude and within a defined volume of rock?' It is most useful when designing support to survive an event that is anticipated based on a track record. The approach is illustrated schematically in 2D by Figure 13(a) with the following steps:

- Step 1: Define maximum expected magnitude of a DE from an analysis of past seismic activity for an acceptable probability of occurrence (or confidence level).

- Step 2: Verify the constant $C^{*}$ for the scaling law or calibrate $C^{*}$ by plotting log $(R \cdot p p v)$ versus log $\left(M_{0} \Delta \sigma\right)(\mathrm{CRBSHB})$.

- Step 3: Define boundaries of a design volume (DV) within which the design event is to be expected. Note: it may be advisable to define several DVs with different design event magnitudes.

- Step 4: Use scaling law to define ground motion at support design locations:

a. Inside a DV, but near critical structures, estimate appropriate near-field ground motions limit (Cai and Kaiser, 2013);

b. Inside a DV but remote from critical structures: use scaling law with $R=R_{\min }$ to obtain $p p v_{D}$; 
c. Outside a DV: use scaling law with source at DV boundary closest to design location; this creates a hallo around the DV of radially decreasing $\mathrm{ppv}_{\mathrm{D}}$. Note: there may be design sectors intersecting the hallo, in which case the higher $\mathrm{ppv}_{\mathrm{D}}$ controls the design.

Accordingly, for the data shown in Figure 13(a), two design volumes ( $A$ and $C$ ) have been identified, each with different maximum event magnitudes $\left(M_{\max A}\right.$ and $\left.M_{\max }\right)$. The corresponding scaling law hallos are shown for both design volumes and are indicated by $B$ and $D$, respectively. In design volume $A$, for drifts near the faults, Step 4(a.) is used to determine the ground motion. In scaling law hallo B, Step 4(c.) is used to determine the ground motion unless the design volume $C$ produces higher $p p v_{D}$. In scaling law hallo $D$, Step 4(b.) should be used to determine the ground motion unless the determined ground motion is less than what is determined in volumes A and B. In scaling law hallo D, Step 4(c.) provides the ground motion unless the value determined is less than what is defined in volume $D$.

This approach provides four design sectors for the determination of support demand from seismic loading. The resulting ground motion profile for a hypothetical tunnel is shown in Figure 13(b). It illustrates how the two design volumes interrelate and which controls the design $\mathrm{ppv}_{\mathrm{D}}$. Within $\pm 40 \mathrm{~m}$ and from -80 and +130 m, design volume A controls; in between design volume B controls.

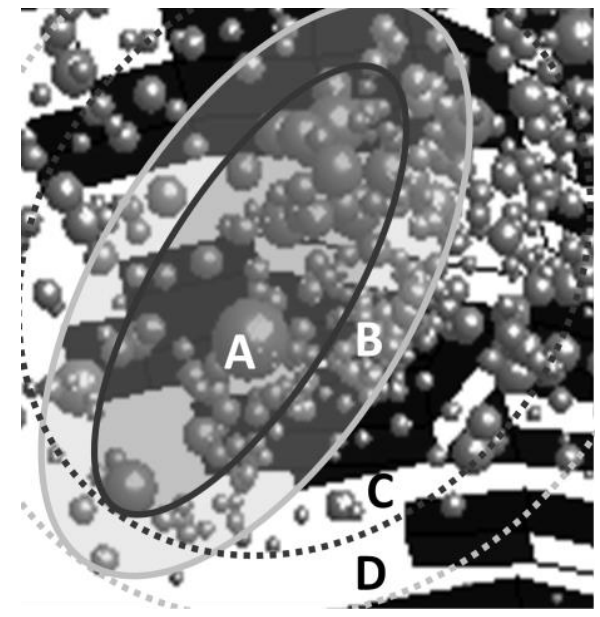

(a)

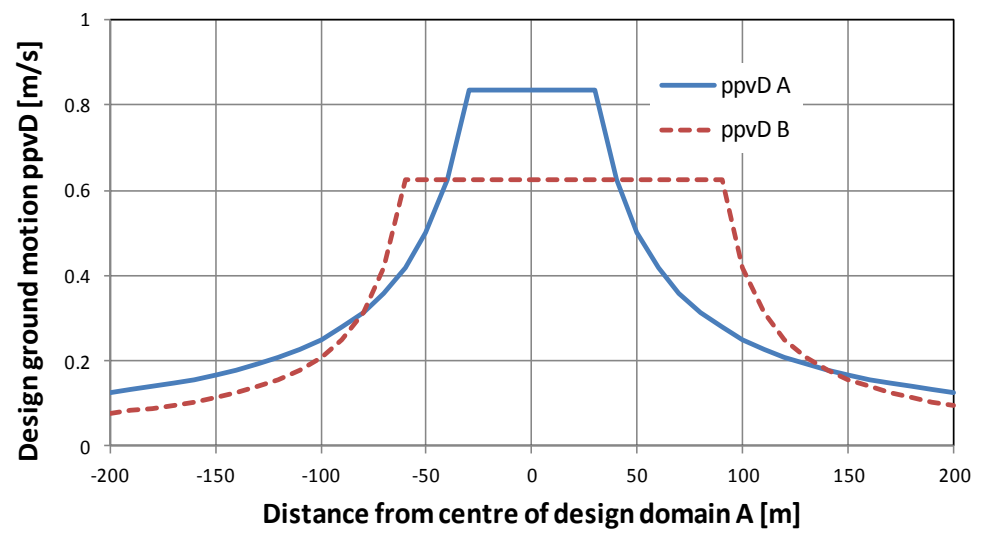

(b)

Figure 13 (a) Schematic illustration of a seismic hazard map approach with two defined design volumes (A with $\boldsymbol{M}_{\max A}$ and $\mathrm{C}$ with $\boldsymbol{M}_{\max C}$ ). The corresponding hallo of decreasing ppv based on scaling law is shown in $B$ and $D$, respectively; (b) resulting $\mathrm{ppv}_{\mathrm{D}}$ along hypothetical drift

Again, this approach cannot be followed in forensic analyses, in which the actual ground motions differ significantly from those obtained in this manner. 


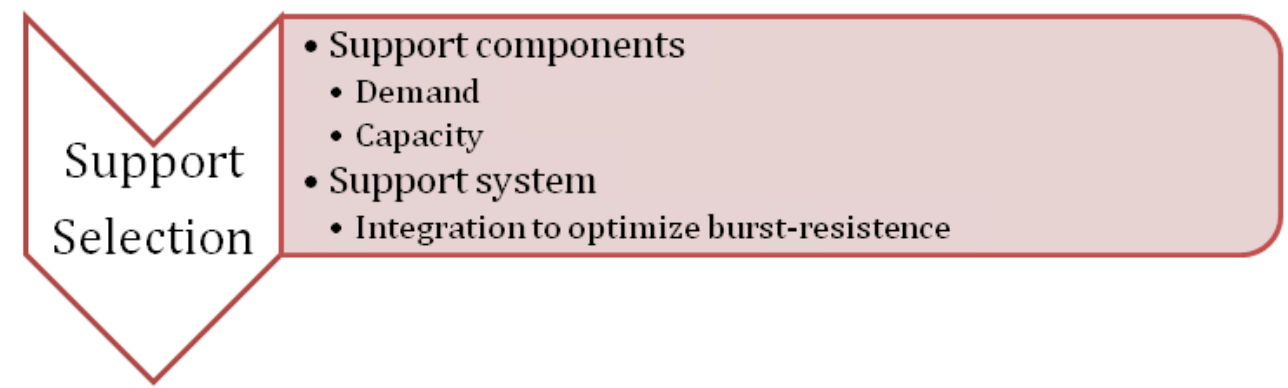

Based on the considerations given previously, it is now possible to establish load, deformation, and energy demands for support design. As indicated above, major deficiencies do not stem from the fundamental approach but from a series of misunderstandings in terms of failure processes and thus dominating design parameters. In the authors' opinion, the approach given in the CRBSHB for support demand and capacity determination is still applicable. However, they have to be applied with respect to the constraints presented in this keynote paper. The reader is therefore referred to Kaiser et al. (1996). In the near future a revised version by Cai and Kaiser (under development for release in 2013) will be available.

\section{$7 \quad$ Design verification - forensic analysis}

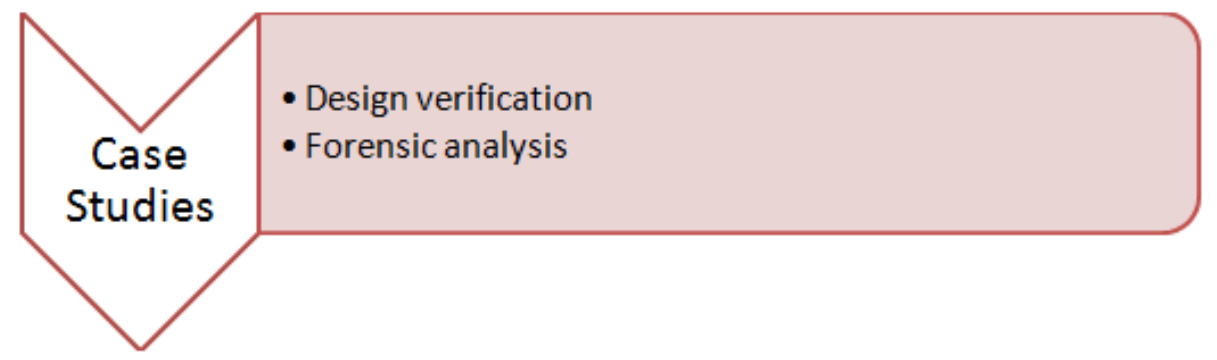

Design verification involves two aspects: (1) verification of design parameters such as $C^{*}$ for the scaling law, and (b) analysis of case studies. Here, we focus on the latter, i.e. a systematic approach for forensic analysis.

Forensic engineering in the context of this paper is the investigation of rockburst processes causing damage to underground excavations. The purpose of a forensic investigation is to locate the cause or causes of failure with a view to improve performance in future comparable situations. Forensic analysis therefore refers to a process whereby damage to an excavation or its support is assessed to better understand the cause of failure or to obtain design parameters. Most importantly, both damaging and non-damaging events should be analysed to identify critical locations and to improve means of reducing excavation vulnerability.

For forensic analyses, the actual ground motion must be measured, which is rarely possible unless a sensor was by chance placed close to the damage location, or predicted by synthetic ground motion (SGM) models.

\subsection{Synthetic ground motion for support design verification}

The use of a scaling law to link ground motion (ppv and ppa) to seismic magnitude (or moment) and the distance from the seismic source is a sound engineering approach that follows principles adopted in other engineering disciplines. However, scaling laws provide design assumptions and not actual ground motions, as explained in Section 5.1.3, because the effect of many factors, i.e. source parameters, fault-slip direction, wave propagation medium, etc., which can introduce large variations in ground motions is intentionally not represented in scaling laws. Because scaling laws provide upper bound values to ground motion measurements (Figure 12), the true ground motions must be measured or anticipated by analytical or 
numerical models producing synthetic ground motions (SGM). Thus, damage to excavations or support is assessed with ground motions derived from SGMs that provide an estimate of anticipated ground motion patterns.

\subsubsection{Synthetic ground motion assessment}

As introduced previously, with support from CEMI, IMS has developed a synthetic ground motion assessment tool, called S-GMAT, which can be used to study SGM patterns emitted from seismic sources. S-GMAT produces analytical ground motion solutions ( $p p v$ and ppa) for point sources in a homogeneous media and numerical solutions for heterogeneous rock masses with reflectors from excavations. By using SGM models such as S-GMAT, ppv and ppa distributions along drift (Figure 12) or contours as illustrated by Figure 11 can be obtained for forensic analyses.

Figure 14 presents contours of ground motion for the same event as shown in Figure 11 but with an open excavation (horseshoe shaped). The $\mathrm{p}$ - and s-wave radiation patterns are shown by the dark and light contours, respectively. Wave reflections lead to a complex wave propagation pattern (shown on the right side for three sensor locations). All three sensors below the excavation show several repeated wave peaks, horizontal and vertical component shown in two shades of grey. While the third sensor, from the top, shows a typical $\mathrm{p}$-followed by an s-wave pulse, with a single delayed reflection, the first and the second sensors show two or three high amplitude wave peaks. Most interestingly, the second sensor, the furthest from the source, experiences the most severe ground motions with three sequential peaks of comparable amplitudes. Potential damage due to seismic loading should therefore be quite different at the three locations and potentially most severe at the second location. On the other hand, the scaling law would produce the highest ppv for the first, the second highest for the third, and the lowest for the third sensor due to the respective proximity to the source.

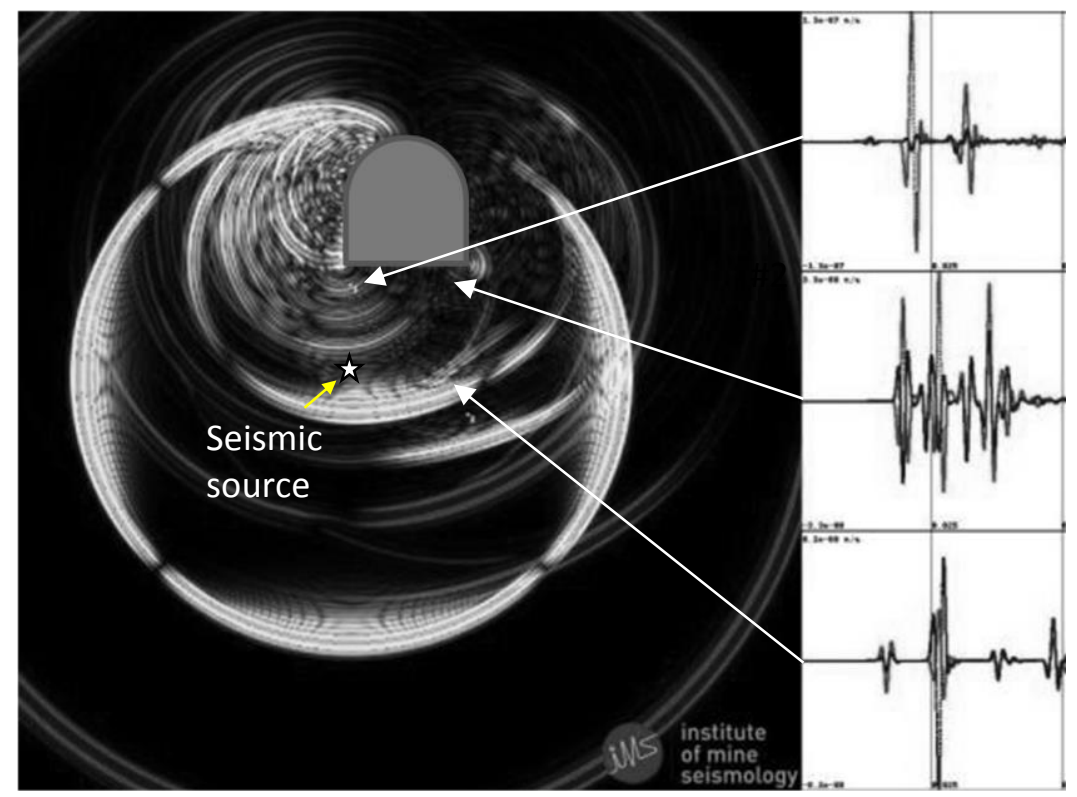

\section{Figure 14 Ground motion contours with synthetic wave forms for three sensors located below excavation}

In summary, the SGM approach generates waveforms by considering the fault-slip mechanism, stress drop, slip direction, rupture velocity, slip time and amount, amongst others. The source waves are then propagated in the media by a nonlinear site response analysis using 3D numerical models that can simulate the influence of excavations and geological structures. SGM models can therefore be adopted for systematic analyses of known seismic events and related damage to excavations. The purpose of such forensic analyses is to better understand the spatial distribution of ground motions, the damage causing factors, and the influence of support on the excavation behaviour. Ideally, field seismic monitoring data can 
be used to evaluate the model outputs. Alternatively, local site-specific ground motion and excavation damage data can be analysed and used to identify local ground motion patterns and thus properly understand causes for excavation and support damage.

\subsubsection{Practical implications}

The adopted design scaling law produced $\mathrm{ppv}_{\mathrm{D}}$ can be verified by comparing the scaling law predictions with the maximum ground motions obtained from numerous events and randomly located sensors. Similarly, the scaling law can be verified by comparison with results from synthetic ground motion simulation. However, only maximum ground motion values are to be matched by the scaling law.

Scaling laws cannot be obtained by fitting all measured data. A best-fit will provide a relationship to obtain the average measured ground motion, meaning that $50 \%$ of the ground motions will be higher and $50 \%$ lower. Such a best-fit relationship is not suitable for support design and violates one of the fundamental engineering design principles, i.e. to design for a threshold value considering a reasonable worst-case scenario, e.g. the equivalent of a hundred year flood. Hence, scaling laws cannot be used for forensic analyses.

Finally, realising that a scaling law provides a fit to the maximum anticipated ground motions, factors of safety used in standard engineering design can be applied to rock support design. If the design follows the principles introduced by Kaiser et al. (1996), there is no need to use elevated factors of safety to cover for uncertainties introduced by dynamic loading factors.

\subsection{Forensic analysis approach}

Heal et al. (2006), amongst others, made great attempts to draw from experience and to interpret findings from case studies. Unfortunately, all these attempts are hampered by the fact that it is difficult, and until now, next to impossible to anticipate the ground motions and related dynamic loading at the damage location. Hence, the results are potentially flawed for reasons explained previously: comparison with design rather than actual ground motions, lack of inclusion of stored strain energy at damage location, lack of consideration of local mine stiffness, lack of differentiation between failure modes, deficiencies in excavation vulnerability potential assessment, amongst others.

Without degrading the empirical value of such investigations and their findings, by considering synthetic ground motions, it is now possible to undertake forensic analyses or case studies in a systematic manner. The approach used for forensic analyses depends on the aims of the analysis: understanding the causes of rockburst damage, assessing the effectiveness of installed support, and verification of design parameters.

Based on these considerations and depending on the objective, the approach varies but the following general guidelines can be provided for forensic analyses of both rockburst damage and no damage situations:

- Step 1: Filtering of damage causes by assessing failure mode.

- Establish the predominant failure mode as stress-driven or gravitational; i.e. separate stress fracturing from falls of ground.

Clearly identify whether damage is caused at least in part by a strainburst. If so, do not relate damage to ground motion analysis alone. Try to answer the following questions: is there evidence of release of local energy? (e.g. high convergence difference suggests locally soft mining system, potentially due to nearby geological structures; stress raisers due to local variability in rock stiffness; etc.); is the related seismic source co-located? (e.g. considering source location error and source parameters, as well as damage mechanisms); is the damage likely caused or dominated by a remote seismic event?

- Step 2: Assess excavation vulnerability potential (EVP). 
- Establish all relevant factors that describe the vulnerability of the excavation at the damage location, and the potential non-vulnerability at nearby stable locations.

Heal et al. (2006) provided an approach for this purpose, suggesting that the following four factors must be included:

- stress conditions (E1), based on major principal stress to intact rock strength (UCS);

- ground support system capacity (E2), based on a rating of support system capacity;

- excavation span (E3), considering size dependence of damage potential; and

- influence of geological structure (E4), rating the influence of persistent structures.

This approach mixes factors for different failure modes. Hence, the EVP index can be improved and the following aspects should be assessed, whether formally rated or qualitatively assessed:

- assess vulnerability separately after filtering for failure mode (fall of ground versus strainbursting, etc.);

- assess local state of stress considering the local stress ratio (using definition of stress level SL presented previously, based on maximum stress near an equivalent circular excavation $\sigma_{\max }=3 \sigma_{1}-\sigma_{3}$, where $\sigma_{1}$ and $\sigma_{3}$ are obtained at a point near the damage location and include mining-induced stresses. Look separately at stress raisers $\left(\sigma_{\max }\right)$ and stress relaxation $\sigma_{\min }=3 \sigma_{3}-\sigma_{1}$;

- assess deficiencies in support system, e.g. did individual support component or connection fail?;

- only consider span if there is a stress relaxation potential in backs or clear evidence of gravity assisted failure; and

- assess the influence of geological structures from the following three perspectives:

- structures that enhance fall of ground potential or ravelling potential (weakness planes facilitating removal of broken rock);

- structures that cause stress raisers (e.g. laminations, etc.); maybe the most important, but also the most difficult to identify;

- structures that change the mine stiffness by penetrating the excavation or being hidden near the excavation.

If, and only if there is clear evidence, that damage is related to and dominated by a remote seismic source (fault-slip), the following step should be followed to interpret the damage:

- Step 3: Obtain ppv profile in damaged areas as illustrated by Figure 12; establish range of ground motions based on available variability in source information established by source mechanism analyses (seismic moment, stress drop, etc.). Do not use scaling laws for this purpose.

- use S-GMAT or similar model to establish ground motion patterns in damaged area and profile along drifts at damage location and at nearby undamaged locations. An example ppv pattern is shown in Figure 15, illustrating the focusing effects of radiation patterns. 


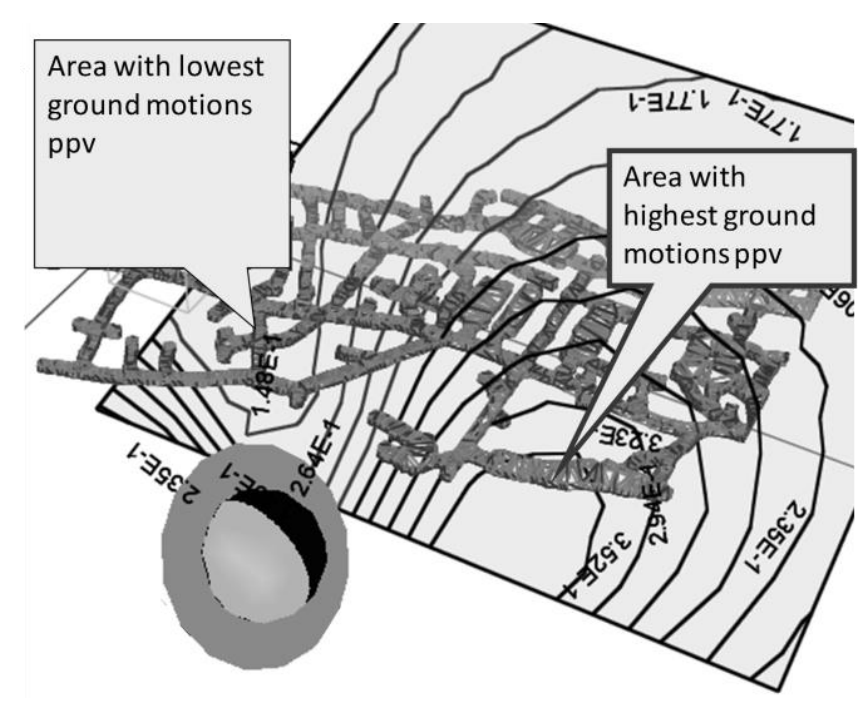

Figure 15 Peak ground motion contours of ppv produced by S-GMAT for a seismic
source shown as a beach ball Finally:

- Step 4: Assess each failure mode and related support demand separately.

- establish which mode is critical and qualitatively consistent with observation: strainburst, fall of ground, dynamic loaded failure mode,

- establish dominant damage causing and thus design criteria (load, displacement, or energy, or a combination of same).

- Step 5: Back-analyses for input and design parameters consistent with the dominant mode of failure and, most importantly, verify conclusions by assessing nearby situations of satisfactory excavation and support performance at stable locations.

This process is currently being followed in a second phase of an industry sponsored program lead by CEMI.

\section{Reassessment of rockburst damage data}

With the benefit of the knowledge gained and the issues addressed previously, it is now possible to review and reassess previously published cases from a new perspective. Two examples are presented here for illustrative purposes.

\subsection{Case study A - seismically triggered strainburst}

This case history presents an example of rockburst damage to drifts excavated using destress blasting. These drifts were damaged by a previous burst event (eleven months prior to this case study, a $m_{N}=2.8$ seismic event caused damage at multiple locations on the 2130 Level) and, thus, serves to illustrate damage processes in drifts that had previously experienced bulking due to fracturing. Most of the drifts on the 2130 Level had been reconditioned after the previous series of rockbursts and were supported by $1.8 \mathrm{~m}$ long mechanical rockbolts, $2.4 \mathrm{~m}$ long resin-grouted rebar, and \#4 gauge welded wire mesh. In some locations, Split Set bolts were also installed in the walls of the drifts and the 4500 Tram drift (Figure 16) had also been shotcreted in the back and walls.

A seismic event with a Nuttli magnitude $m_{N}=2.9$ was located at a depth of 2,120 $\mathrm{m}$ and caused rockburst damage on the 2070 (not shown) and the 2130 Levels (Figure 16) at about $260 \mathrm{~m}$ from the source. A crown pillar ( 2010 to 2130 Level) and a vertical retreat mining (VRM) panel ( 2130 and 2190 Level) were blasted at the end of an afternoon shift. Following these blasts, seismic activity increased substantially in the footwall 
area. The remote seismic event was believed to have triggered several small rockbursts (strainbursts) in various drifts on the 2130 Level. It also triggered small rockbursts at two locations on the 2070 Level.

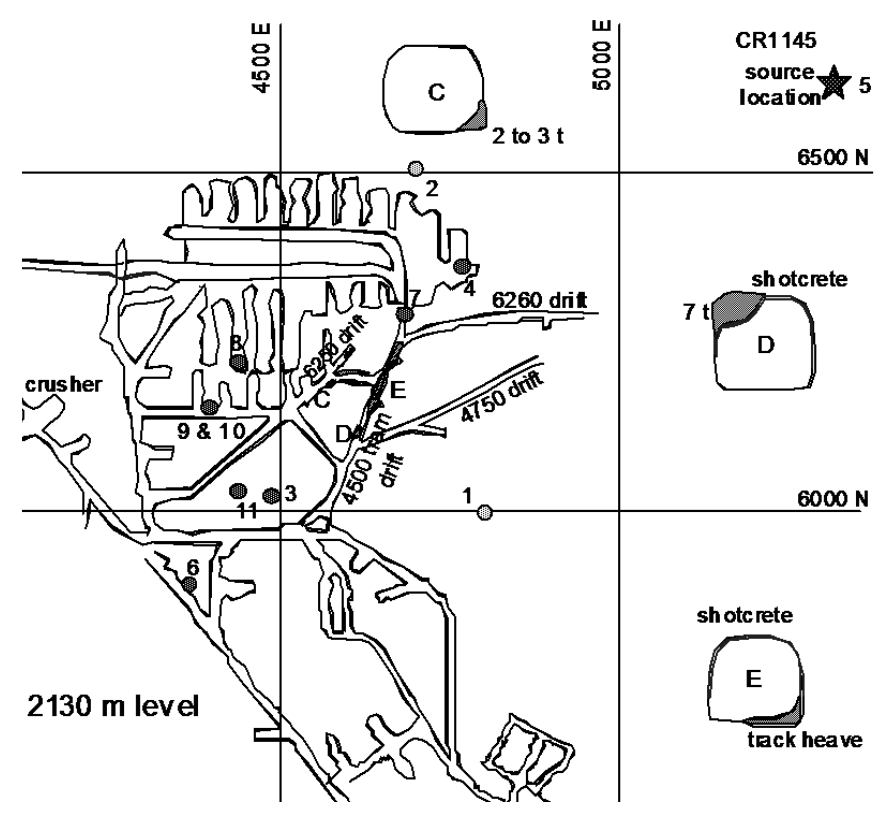

\section{Figure $16 \quad 2130 \mathrm{~m}$ Level showing rockburst damage locations and locations of two blasts (1 and 2) and related seismic events (3 to 11) (1996 CRBSHB)}

The seismic monitoring system at the mine produced source locations of the blasts that do not correspond with any of the mining areas and hence may have an error of about 10 to $20 \mathrm{~m}$. Consequently, the source location error of the subsequent seismic activity may be of the same order of magnitude.

Nearly three minutes after the blasts, a $m_{N}=1$ event (\#3) occurred. It was followed by a $m_{N}=1.2$ event (\#4), almost two hours after the blast, and the largest seismic event $\left(m_{N}=2.9\right.$; \#5) near the 2130 Level, 195 minutes after the production blasts. Ten seconds later, a $m_{N}=1.3$ seismic event occurred near the footwall on 2040 Level. These events were followed by seven smaller seismic events over a period of six hours with magnitudes ranging from 0.9 to 1.4 .

\subsubsection{Geology and stresses}

The failed rock at the rockburst locations was footwall gabbro and metagabbro with quartz-carbonate filled vertical joints. No dominant geological structures were located near any of the rockbursts. The unconfined compressive strength of the gabbro was in the order of $240 \mathrm{MPa}$. The far-field stresses in the vicinity of the 2130 Level were estimated as: $\sigma_{1}=100 \mathrm{MPa}$ east to west, $\sigma_{2}=79 \mathrm{MPa}$ north to south, and $\sigma_{3}=62 \mathrm{MPa}$ vertical; resulting in pre-mining stresses of $\sigma_{\max N / S}=238 \mathrm{MPa}$ in drifts running north-south, and $\sigma_{\max E / W}=$ $175 \mathrm{MPa}$ in the back and floor of the drifts running east-west. For the pre-mining stress state, the corresponding static depth of failure was estimated as $1.5 \mathrm{~m}$ the back and floor, and near zero in the walls. Drifts running east-west were less stressed and hence, should display less fractured rock. These estimates were, in general, confirmed by observations underground (Langille, pers. comm., 2013). These stresses might have been altered by mining activities above and below and this was reflected in the rotated damage patterns shown in Figure 16.

\subsubsection{Rockburst damage}

The seismic events resulted in rockburst damage on two levels of the mine. A total of $12 \mathrm{t}$ of rock was found on the floor. The damage locations are shown by the shaded areas in Figure 16 and described below for the 4500 Tram Drift (Kaiser et al., 1996).

The 4500 Tram Drift sustained most of the rockburst damage. Near the intersection with the 4750 Drift along the north-west wall, rockburst damage resulted in the bulking of roughly six tonnes of rock. The 
fractured rock bulged the mesh and shotcrete into the drift but the broken rock was retained by the mesh and shotcrete. An old rockbolt was broken at the location of the bagged mesh and shotcrete (Figure 4(b)). During rehabilitation of this area after the rockburst, the depth of failed rock was found to be about 1.2 to $1.5 \mathrm{~m}$. Rockburst damage also resulted in the bulking of a $0.3 \mathrm{~m}$ thickness of rock over a $1 \mathrm{~m}$ height above the floor along the south wall of the 4500 Tram Drift from the intersection at the 4750 Drift, north for $50 \mathrm{~m}$ to the corner. The floor of the drift was also damaged, resulting in track heave of up to $0.3 \mathrm{~m}$. Numerous shards of rock and fracturing in the back were observed in the 4750 Drift but no substantial displacement of rock was noted.

\subsubsection{Ground motion at rockburst locations}

Assuming accurate source locations, the peak particle velocities at the 4500 Tram Drift were estimated at $\mathrm{ppv}=60$ to $110 \mathrm{~mm} / \mathrm{s}$ for the largest event and ppv $=20$ to $50 \mathrm{~mm} / \mathrm{s}$ during subsequent shaking by the eight subsequent seismic events. These peak particle velocities were relatively small with the first event causing a maximum dynamic stress increment of about $3 \mathrm{MPa}$ and the following events adding about $1 \pm 0.5 \mathrm{MPa}$ each, assuming perfect source location accuracy. These stress increments were between 1 and $2 \%$ of the static stress near the drifts and would cause negligible deepening of the depth of failure, estimated increment of about 5 to $30 \mathrm{~mm}$ for each event. The cumulative deepening of the fracture zone for the nine events would be in the order of 0.1 to $0.15 \mathrm{~m}$. With a bulking factor of 5 to $10 \%$ for the freshly fractured rock, this would lead to incremental wall displacements of 10 to $15 \mathrm{~mm}$. Such small incremental deformations can be sustained by most support elements, as long as they are not already loaded to their capacity. If unsupported or only lightly supported, increased bagging of mesh and loosening of previously fractured rock must be expected. Floor heave of about 0.1 to $0.2 \mathrm{~m}$ would also be anticipated. These predictions corresponded well with the actual observations of floor heave, localised loading of support, and spalling near the floor. Furthermore, the shotcrete only bulged where an old bolt failed, lending credibility to this analysis (Figure 4(b)).

Hence, the support in the area must be able to tolerate incremental deformations from incremental failure around the excavation. The damage process in this example therefore should be classified as repeated, seismically triggered strainbursts resulting from fault-slip due to mining-induced stress changes. The observed damage here cannot be used to calibrate dynamic input parameters or the scaling law.

\subsection{Case study B - excavation vulnerability and damage potential}

Heal et al. (2006) established a substantial database of rockburst damage severity and causes and proposed an excavation vulnerability potential (EVP) index to assess the vulnerability of an excavation to damage by a rockburst. In their data analysis, they related the damage severity, with a rating from R2 to R5, to the ground motion obtained by the design scaling law $\mathrm{ppv}_{\mathrm{D}}$ and suggested that there was a probability function to relate damage potential to this ground motion (Figure 17). They concluded "The figure shows ... that for a given magnitude seismic event at a given distance from the excavation, there is a strong relation between EVP and the amount of rockburst damage done." The probability lines also suggest a strong dependence on seismic event related ground motions. 


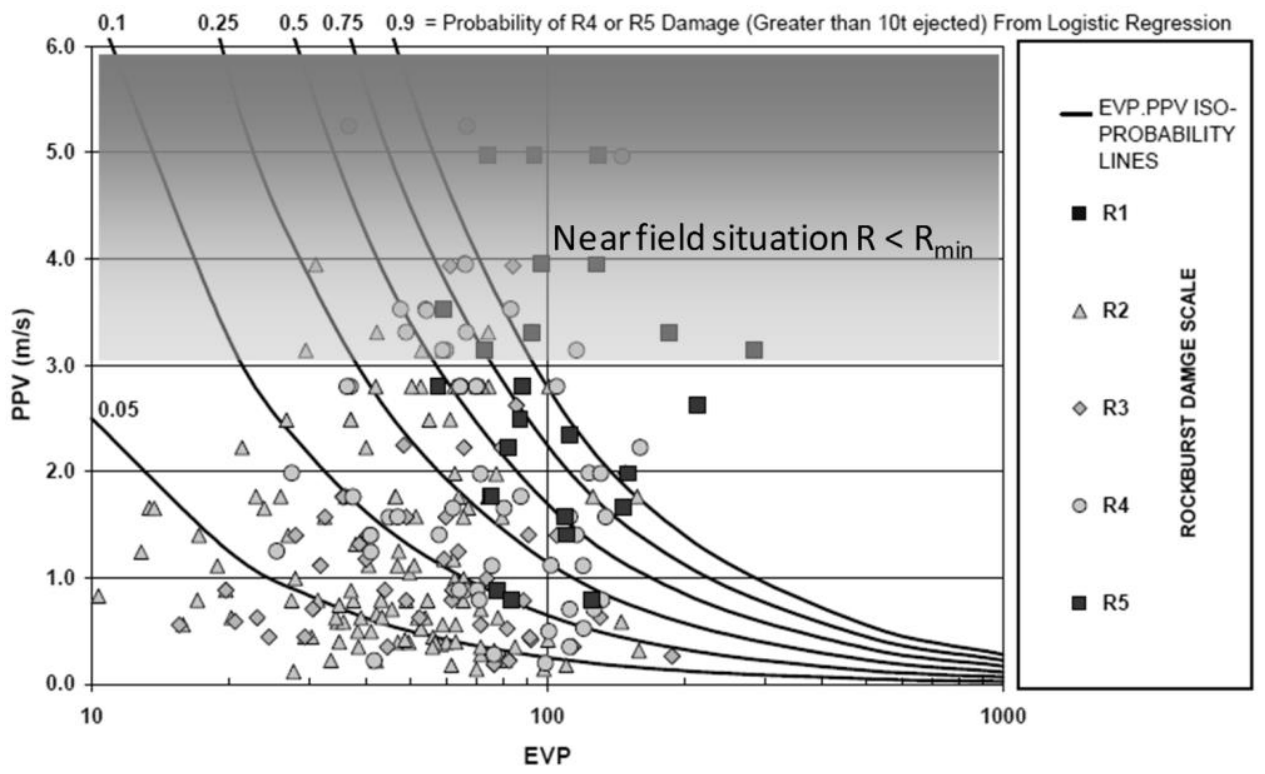

Figure 17 EVP versus estimated $\mathrm{ppv}_{\mathrm{D}}$ for 254 damage locations (modified from Heal et al., 2006)

The study by Heal et al. (2006) and thus Figure 17 presents extremely valuable data and the first author wishes to acknowledge the generous provision of this data by Heal et al. for inclusion in this paper. This allowed the author to reinterpret some of the data considering the issues discussed in this keynote and to identify several deficiencies that require further study.

First, the scaling law provides design values $p p v_{D}$, not actual ground motions as should be used for forensic analysis. The actual ppv-values at the damage locations are expected on average to be significantly lower than those estimated for Figure 17; unless the source was critically oriented relative to damage location in each case (which is unlikely).

Second, the design scaling law should only be applied to openings in the far-field, at distances greater than $R_{\min }$ from the seismic source (Kaiser and Maloney, 1997). For the magnitude range of 0 to 3.5 of this study and for an assumed range of stress drops between 1 and $10 \mathrm{MPa}, R_{\min }$ would range from about 15 to $30 \mathrm{~m}$. For $50 \%$ of the cases presented in Figure 17, the distance to the seismic source is less than $15 \mathrm{~m}$ and for all cases less than $70 \mathrm{~m}$. Thus, most cases are in the near-field. McGarr (1984) showed, based on laboratory evidence and a well-accepted dynamic rupture model (Madariaga, 1976), that near-fault or near-field ground motions are limited or bounded. Based on his recommendations with typical input parameters, upper-bound values for near-field ppv should range from 3 to $4 \mathrm{~m} / \mathrm{s}$. For this reason, data in the shaded area in Figure 17 are most questionable with respect to ground motion intensity. Of course there are reasons why higher ppv-values might be measured but values exceeding 3 to $4 \mathrm{~m} / \mathrm{s}$ are certainly outside the range of applicability of scaling laws.

Most importantly, considering typical source location accuracies for mines and the above considerations, it is suspected that in most cases, damage and source are co-located, as would be expected for strainbursts. If this was the case, most if not all of the damage reported by Heal et al. (2006) should be classified as either seismically triggered or dynamically loaded strainbursts (as in previous case study in Section 8.1) or as seismically triggered or dynamically loaded falls of ground (Kaiser et al., 1996).

With this in mind, the data was re-plotted in Figure 18(a) and grouped by damage severity from R2 to R5. Despite the wide scatter, linear regression, minimising variability in EVP, shows little to no dependence on the calculated design ground motions $\mathrm{ppv}_{\mathrm{D}}$. For each group, the damage severity is more or less constant for $p p v=0.1$ to $3.5 \mathrm{~m} / \mathrm{s}$. On average, this is even true for the highest damage level R5. Visual inspection suggest, as would be expected, that the most vulnerable excavations are most prone to severe damage (R4 and R5). 
If none of the cases were related to ground motion intensity, as would be expected for seismically triggered strainbursts or falls of ground, the damage severity should be directly related to the excavation vulnerability. Hence, Figure 18(b) presents the same data in a plot of damage severity against excavation vulnerability. Despite the deficiencies in the EPV noted earlier, as indicated above and as expected, there is a clear trend of increasing damage severity with increasing excavation vulnerability.

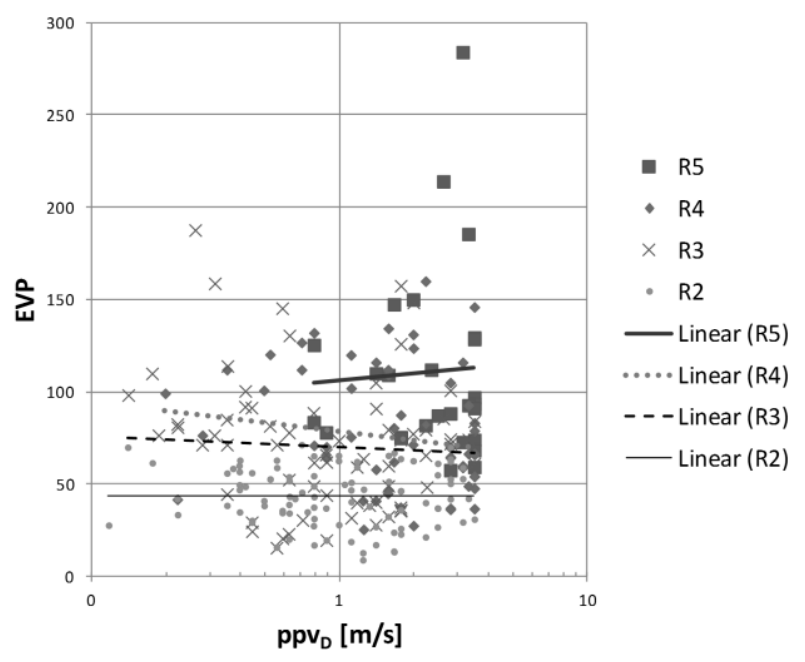

(a)

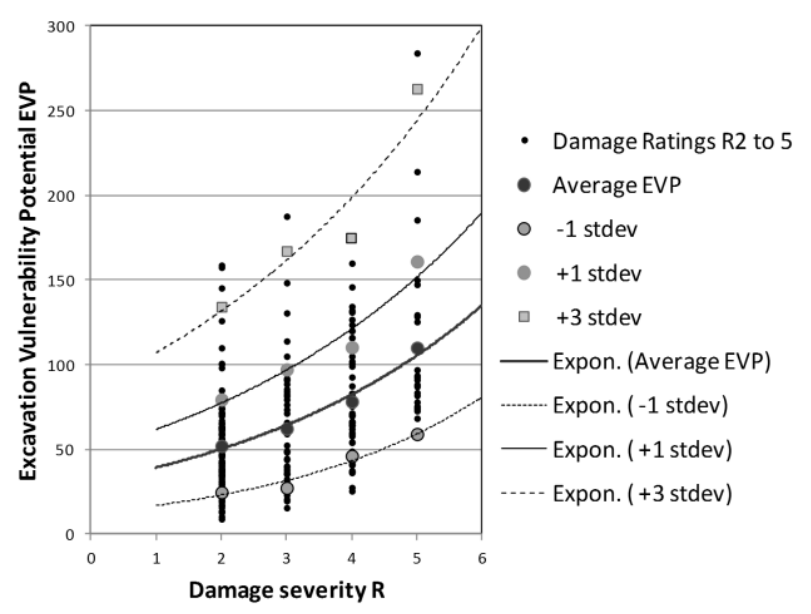

(b)

Figure 18 (a) Estimated $p v_{D}$ versus EVP for 254 damage locations reported by Heal et al. (2006); all data with $\mathrm{ppv}_{\mathrm{D}}>3.5 \mathrm{~m} / \mathrm{s}$ plotted at $3.5 \mathrm{~m} / \mathrm{s}$ ); (b) same data plotted for each damage severity level

The trend lines shown in Figure 18(b) are of the form: damage severity level $R_{i}=A^{-1} \ln (E V P / B)$ with mean $A=0.25$ and $B=30\left(R^{2}=0.22\right.$ on all data; $R^{2}=0.98$ on mean damage severity level $R_{i}$ (black dots near 'Average EVP')). The range for \pm 1 standard deviation in EVP and an upper bound fit for three standard deviations +3 std $(A=0.21 ; B=87)$ is also shown. Accordingly, there is a $50 \%$ chance that an excavation with an EVP, according to classification by Heal et al. (2006), between 80 and 120 will be severely damaged $(>\mathrm{R} 4)$. For an $E V P>12$, about two of three cases are expected to be severely damaged ( $>R 4)$.

In the authors' opinion, this database is mostly populated with failure mechanisms that must be classified as seismically triggered or dynamically loaded strainbursts or falls of ground. The EVP index developed by Heal et al. (2006) captures some but not all of the factors that are critical for these failure modes, i.e. stress level (E1), support capacity (E2), span (E3; only relevant for falls of ground), and geological structures (E4; 
mostly relevant for falls, but also for strainburst potential). It does not include a factor that rates the local mine stiffness.

Most importantly, this reassessment suggests that the severity of damage is dominated by the excavation stability margin (safety margin) rather than the intensity of the related seismic event. With respect to support design, this means that support should, if economically possible, be designed to prevent seismically triggered falls of ground or seismically triggered strainburst and to survive the sudden deformation or straining associated with related rock mass bulking.

\section{Conclusions}

The issues addressed in this keynote suggest that it is definitely 'time to re-think' and to question some of the assumptions made when assessing rockburst damage and by implication when designing support in burst-prone ground.

First, the often assumed direct relationship between ground motion (ejection energy) and yielding support demand is overly simplistic and in many situations wrong. In some cases, the ejection velocity can be very small and if assessed by the energy criterion, the energy demand would be small. This does not imply that yielding bolts are not required in burst-prone mines but for a different reason, i.e. to survive large sudden deformations during violent bulking (strainbursting). When overstressed and highly strained, brittle rock breaks into cohesionless blocky ground, it bulks gradually or suddenly due to a geometric misfit of fragments, and causes large deformations. While the solution may be the same, i.e. a need for yielding bolts, the design criterion is not energy demand but strain or displacement demand.

Second, it is suggested that much of the damage in mine drifts is caused by either seismically triggered strainburst or falls of ground. In both cases the load or deformation demand should be independent of the source characteristics but entirely dependent on the locally releasable energy. Ensuring an adequate static FoS of an excavation, i.e. maintaining a sufficient static safety margin, is then most critical to control the behaviour of an excavation during both gradual mining-induced stress changes and dynamic shaking or loading. This safety margin must be assessed and maintained with respect to load, deformation, and potentially energy. It is therefore suggested that support in burst-prone mines should first be selected or designed considering factors that influence strainbursts (stress level, mining system stiffness, depth of stress fracturing or depth of failure) and factors that influence falls of ground (geological structures, extent of rock mass fracturing, etc.). The effect of ground motions with respect to support design and energy demand requirements seem to be overrated.

Third, only for excavations very close to a large fault-slip event will the dynamic loading impact dominate over the demand from locally stored energy. In this case, damage will be affected by the dynamic load imposed by the event as well as by the energy transferred from the event, and the commonly adopted relationships between ground motion intensity and support energy capacity are applicable.

Fourth, actual and design ground motions are not identical. The former are affected by radiation patterns and wave transmission modifiers. They are needed for forensic analyses and it is suggested that this is best achieved with synthetic ground motion models. The latter are needed for design, that is to anticipate reasonable estimates of extreme ground motions; ground motions that could do damage to an excavation and thus to ground support. These two ground motions should not be confused and arguments against the use of scaling laws are misguided by an incorrect assumption that the two should be the same.

Future research therefore must focus on the interpretation of damage records by use of proper forensic analysis procedures. Two tools, BurstSupport and S-GMAT have been developed for this purpose.

\section{Acknowledgement}

The authors wish to thank Dr D. Heal for providing his database for revaluation within the frame work of this paper. While highlighting in this paper some deficiencies in the approach presented by Heal et al. (2006), the author wishes to acknowledge their most valuable contributions and encourages the reader to 
consider their contribution as an important stepping-stone toward systematic forensic analyses. Unfortunately, at the time, their work was limited by the fact that actual ground motions could not be obtained by synthetic ground motion models, a deficiency that is now overcome.

Furthermore, the financial and in-kind contributions from LKAB, VALE, Rio Tinto, NSERC, CEMI, IMS and MIRARCO are thankfully acknowledged.

\section{References}

Cai, M. and Kaiser, P.K. (2013) A Guide to Rockburst Support Selection (unpublished; for release in 2013/24).

Cai, M., Kaiser, P.K. and Duff, D. (2012) Rock support design in burst-prone ground utilizing an interactive design tool, in Proceedings 46th US Rock Mechanics/Geomechanics Symposium, 24-27 June 2012, Chicago, ARMA, Virginia, 9 p.

Cai, M. and Kaiser, P.K. (2011) Rock support for deep tunnels in highly stressed rocks, in Proceedings 12th ISRM Congress, Y. Zhou (ed), 18-21 October 2011, Beijing, China, pp. 1467-1472.

Cai, M., Champaigne, D. and Kaiser, P.K. (2010) Development of a fully debonded conebolt for rockburst support, in Proceedings Fifth International Seminar on Deep and High Stress Mining (Deep Mining 2010), M. Van Sint Jan and Y. Potvin (eds), 6-8 October 2010, Santiago, Chile, Australian Centre for Geomechanics, Perth, pp. 329-342.

Cai, M. and Kaiser, P.K. (2007) The role of rock support in highly stressed ground support design and selection rationale, Phase-I Report submitted to Rio Tinto, Geomechanics Research Centre, Laurentian University, Sudbury, Ontario, $36 \mathrm{p}$.

Diederichs, M.S., Carvalho, J.L. and Carter, T.G. (2007) A modified approach for prediction of strength and post yield behaviour for high GSI rock masses in strong, brittle ground, in Proceedings 1st Canada-U.S. Rock Mechanics Symposium, 27-31 May 2007, Vancouver Canada, pp. 249-257.

Diederichs, M.S. (2003) Rock fracture and collapse under low confinement conditions, Rock Mechanics and Rock Engineering, Vol. 36(5), pp. 339-381.

Heal, D., Potvin, Y. and Hudyma, M. (2006) Evaluating rockburst damage potential in underground mining, in Proceedings 41 st U.S. Symposium on Rock Mechanics (USRMS), 17-21 June 2006, Golden, USA, 12 p.

Hoek, E., Kaiser, P.K. and Bawden, W.F. (1995) Support of Underground Excavations in Hard Rock, A.A. Balkema, Rotterdam, 215 p.

Kaiser, P.K. (2005) Tunnel stability in highly stressed, brittle ground - Rock mechanics considerations for Alpine tunnelling, Geologie und Geotechnik der Basistunnels, in Proceedings Geological AlpTransit Symposium (GEAT'05), 26-30 September 2005, Zürich, Switzerland, pp. 183-201.

Kaiser, P.K. (2006) Rock mechanics considerations for construction of deep tunnels in brittle rock, in Proceedings 4th Asian Rock Mechanics Symposium, C.F. Leung and Y.X. Zhou (eds), 8-10 November 2006, Singapore, pp. 47-58.

Kaiser, P.K. and Cai, M. (2013a) Critical review of design principles for rock support in burst-prone ground? Time to rethink!, in Proceedings Seventh International Symposium on Ground Support in Mining and Underground Construction, Y. Potvin and B. Brady (eds), 13-15 May 2013, Perth, Australia, Australian Centre for Geomechanics, Perth, pp. 3-38.

Kaiser, P.K. and Cai, M. (2013b) Rockburst damage mechanisms and support design principles, Keynote at RaSiM8, Russia, to be submitted.

Kaiser, P.K. and Kim, B-H. (2008) Rock mechanics challenges in underground construction and mining, in Proceedings First Southern Hemisphere International Rock Mechanics Symposium (SHIRMS), Y. Potvin, J. Carter, A. Dyskin and R. Jeffrey (eds), Vol. 1 Mining and Civil, 16-19 September 2008, Perth, Australia, Australian Centre for Geomechanics, Perth, pp. 23-38.

Kaiser, P.K., Vasak, P., Suorineni, F.T. and Thibodeau, D. (2005) New dimensions in seismic data interpretation with 3-D virtual reality visualization in burst-prone ground, in Proceedings Sixth International Symposium on Rockburst and Seismicity in Mines (RaSiM6), Y. Potvin and M. Hudyma (eds), 9-11 March 2005, Perth, Australia, Australian Centre for Geomechanics, Perth, pp. 33-47.

Kaiser, P.K., Diederichs, M.S., Martin, C.D., Sharp, J. and Steiner, W. (2000) Underground Works in Hard Rock Tunnelling and Mining, in Proceedings International Conference on Geotechnical and Geological Engineering (GeoEng2000), 19-24 November 2000, Melbourne, Australia, pp. 841-926.

Kaiser, P.K. and Maloney, S.M. (1997) Scaling laws for the design of rock support, Pure and Applied Geophysics, Vol. 150(3-4), pp. 415-434.

Kaiser, P.K., McCreath, D.R. and Tannant, D.D. (1996) Canadian Rockburst Support Handbook, Mining Research Directorate, Sudbury, Canada, 314 p. also Drift support in burst-prone ground. CIM Bulletin, Vol. 89(998), pp. 131-138.

Madariaga, R. (1976) Dynamics of an expending circular fault, Bulletin of the Seismological Society of America, Vol. 66, pp. 639-666.

Martin, C.D., Kaiser, P.K. and McCreath, D.R. (1999) Hoek-Brown parameters for predicting the depth of brittle failure around tunnels, Canadian Geotechnical Journal, Vol. 36(1), pp. 136-151.

Martin, C.D. (1997) Seventeenth Canadian Geotechnical Colloquium: The effect of cohesion loss and stress path on brittle rock strength, Canadian Geotechnical Journal, Vol. 34(5), pp. 698-725.

McGarr, A. (1984) Scaling of ground motion parameters, state of stress, and focal depth, Journal of Geophysical Research, Vol. 89, pp. 6969-6979.

Salamon, M.D.G. (1970) Stability, instability, and design of pillar workings, International Journal of Rock Mechanics and Mining Sciences, Vol. 7, pp. 613-631.

Trollope, D.H. (1968) The Mechanics of Discontinua or Clastic Mechanics in Rock Problems, Rock Mechanics in Engineering Practice, K.G. Stagg and O.C. Zienkiewicz (eds), John Wiley \& Sons, New York, pp. 275-320. 
Keynote address 